\title{
La imagen de la bicicleta en la comunicación publicitaria: movilidad sostenible y cambio climático
}

\author{
Advertising image of the bicycle: sustainable mobility and climate \\ change
}

\author{
Gerardo Pedrós-Pérez, ${ }^{1}$ Pilar Martínez Jiménez² y Pilar Aparicio Martínez ${ }^{3}$
}

Fecha de recepción: 17-03-2020 - Fecha de aceptación: 16-06-2020

Hábitat y Sociedad (ISSN 2173-125X), n. ${ }^{\circ} 13$, noviembre de 2020, pp. 125-149.

http://dx.doi.org/10.12795/HabitatySociedad.2020.i13.08

\section{Summary}

Active mobility has been described as a healthy action, it also contributes to diminish climate change and improvethe air quality. Research the advertisements in the roles of mobility from anenvironmental and energy point of view is highly relevant. In this analysis the bicycle appears as an added element, from company campaigns to institutional advertising, and also of specific advertisements where bicycles are directly marketed. This study had as objective to provide a novel analysis of adverting regarding bicycle and mobility. A quantitative and qualitative analysis has been carried out based on diverse publicizing documents spread during the last twenty years. Based on the analysis, the results showed how the role of the bicycle presented in publicity not related about mobility seems to be equal better communication between people, transport, fun and healthy element good and bad practices identified and analyzed in both corporate and institutional campaigns. Also, some bicycle advertisements reuse the slogans for automobiles, focusing on gadgets or design. Based on the analysis, it would be wise to insist on the development of communication guides that focus on the bicycle as an element of the smart city, electric mobility, zero emissions vehicle and healthy transport, both from individual and collectivebeneficial perspective.

\section{Key words}

Environmental advertising; Bicycle advertising; Sustainable mobility; Health

\section{Resumen}

La movilidad activa es saludable, contribuye a mitigar el cambio climático y a mejorar la calidad del aire. La investigación sobre los contenidos medioambientales y energéticos de la publicidad de la movilidad es de gran trascendencia. La gran novedad que aporta este estudio es el análisis de la publicidad donde aparece la bicicleta. Este artículo incluye campañas de empresas, publicidad institucional, y anuncios específicos en los que se comercializan directamente bicicletas. Se ha realizado un análisis tanto cuantitativo como cualitativo basado en el material recopilado por los autores en más de veinte años. El papel de la bicicleta en productos no relacionados con la movilidad suele ser sinónimo de mejor comunicación entre las personas, transporte, diversión y elemento saludable. Se detectan y analizan buenas y malas prácticas tanto en campañas de empresas como institucionales. Algunos anuncios de bicicletas recurren a los mismos eslóganes que los de los automóviles: gadgets, diseño, tecnología, etc. Se recomienda el desarrollo de guías de comunicación que insistan en la bicicleta como elemento de la Smart City, movilidad eléctrica, vehículo cero emisiones y transporte saludable tanto con beneficios individuales como colectivos.

\section{Palabras clave}

Publicidad ambiental; Publicidad de la bicicleta; Movilidad sostenible; Salud

\footnotetext{
1 Catedrático de Escuela Universitaria del Departamento de Física Aplicada. Universidad de Cordoba, España. E-mail: fa1pepeg@ uco.es. ORCID: 0000-0003-4585-9786

2 Catedrática del Departamento Física Aplicada. Universidad de Córdoba, España. E-mail: fa1majip@uco.es. ORCID: 0000-00028680-5250

3 Profesora sustituta interina a tiempo completo del Departamento Enfermería. Universidad de Cordoba, España. E-mail: n32apmap@uco.es. ORCID: 0000-0002-2940-8697
} 


\section{Planteamiento del problema}

En las investigaciones más recientes, presentadas tanto como comunicaciones a congresos como en artículos de investigación (Haufe, Millonigy y Markvica, 2016), al transporte o desplazamiento mediante tracción humana (bicicleta, caminante, etc.) se le denomina genéricamente "Movilidad Activa", en inglés Active Mobility. La Movilidad Activa se caracteriza por ser sostenible, saludable, sin restricción de edad y ligada a la actividad física. Por el contrario, a la movilidad motorizada se la conoce como movilidad pasiva. Actualmente, existe un alto grado de consenso dentro de la comunidad científica respecto al estudio y promoción de la movilidad en bicicleta como medio para conseguir ciudades más sostenibles y mejorar la salud de sus habitantes (Fishman y Cherry, 2015).

La bicicleta sería equivalente a una vacuna de salud pública. La bicicleta es un medio de movilidad activa, sin restricción de edad, a la que pueden acceder tanto niños como personas mayores. Más allá de este aspecto con respecto a la edad, es necesario plantear la siguiente cuestión: ¿Qué puede aportar la bicicleta a la movilidad activa? Contribuye a la facilidad de desplazamientos a los barrios más alejados. En 30 minutos es posible recorrer fácilmente 7 kilómetros en bicicleta. Un ciclista promedio desarrolla una potencia de aproximadamente 184 vatios $(\mathrm{W})$.

Frente a las notables características reseñadas, se observa, sin embargo, que la investigación sobre la publicidad de la movilidad en bicicleta, cuyo análisis se centra en aspectos de salud, medioambientales y energéticos, es muy escasa. El objetivo fundamental en la investigación llevada a cabo por nuestro equipo, y que se presenta en este trabajo, es el análisis de la publicidad en el que la bicicleta aparece como elemento añadido, desde campañas de empresas, hasta publicidad institucional, y también de anuncios específicos donde se comercializan directamente diferentes modelos de bicicletas.

La hipótesis inicial que se planteó para este estudio fue comprobar si las numerosas características medioambientales y de salud relacionadas con la Movilidad Activa se manifiestan explícitamente en la publicidad comercial o institucional de las bicicletas.

El interés es que un enfoque bien planteado de estas campañas publicitarias podría contribuir a informar, crear y reforzar una nueva cultura de la movilidad activa, saludable y sostenible, y también ayudaría a realzar una de las medidas individuales que tienen mayor impacto en la mitigación del cambio climático, la denominada living car-free (Wynes y Nicholas, 2017).

\section{Antecedentes}

Los contenidos publicitarios reflejan, a veces de manera muy explícita, una de las formas de contaminación más peligrosas y dañinas: la contaminación ideológica (Pedrós-Pérez, 2005).Durante los últimos años se han publicado numerosas investigaciones en el ámbito de la comunicación sobre las implicaciones de la llamada publicidad verde (PedrósPérez y Martínez-Jiménez, 2010; Leonidou, Leonidou, Palihawadana y Hultman, 2011; Fowler III yClose, 2012; Atkinson, 2014; Nyilasy, Gangadharbatla y Paladino, 2014; Atkinsony Kim, 2015; Sabre, 2014; Leonidou, Leonidou, Hadjimarcou y Lytovchenko, 2014; Scopa, Scapella- 
to, Perissinotto, Trevisan, Carrieri y Bartolucci, 2016). En ocasiones los valores, actitudes y comportamientos promovidos por la publicidad comercial pueden ser considerados como social y medioambientalmente inapropiados (Nyilasy et al., 2014; Sabre, 2014; Leonidou et al., 2014). Lo anterior ha guiado a diferentes instituciones públicas, ONG y al sector de la publicidad en España a desarrollar ciertas iniciativas cuyos objetivos son prevenir estas malas prácticas (AUC, 2004; OAPM, 2020; Autocontrol, 2016).

Como antecedentes a la investigación sobre publicidad de la movilidad llevada a cabo en este artículo existen diversas aportaciones que abordan de una forma crítica la publicidad de los coches. En este sentido, algunos autores destacan la relevancia de la publicidad del automóvil en la falta de éxito de las políticas de transporte cuyo objetivo es la mitigación del cambio climático (Goulden, Ryle y Dingwall, 2014). Subrayan que el continuo impulso de una cultura de movilidad que podríamos denominar "cochista" obstaculiza cualquier campaña institucional de la Administración para la promoción del transporte sostenible. No solamente porque en esta publicidad de la industria los coches son presentados como los medios más habituales y ordinarios de transporte, sino también porque estos anuncios muestran y promueven algunos comportamientos relacionados con altas emisiones (Urry, 2010).

Las compañías fabricantes tienen, por tanto, una responsabilidad social en lo que se refiere a la exaltación y mantenimiento de determinados comportamientos contrarios a la racionalidad en el uso de los vehículos a motor y a los criterios de movilidad sostenible (Pedrós-Pérez, 2005).

Son muy pocos los estudios recientes que analizan desde un punto de vista ambiental la publicidad empresarial y/o institucional de la movilidad en los diferentes medios de transporte. En España destaca la interesante aportación sobre anuncios de coches eléctricos de Botey López, Martín Guart y Rom Rodríguez(2013), aunque no abordan los daños colaterales ambientales de los vehículos eléctricos que se desvelan en otras investigaciones (Amato, Pandolfi, Escrig, Querol, Alastuey, Pey, Pérez y Hopke 2009).

Un estudio llevado a cabo por Jiménez Gómez (2017) concluye que sectores como la energía o la automoción han sustituido en sus anuncios el "verde naturaleza" por el "azul tecnología limpia". El autor ilustra este cambio con el ejemplo que se expone a continuación. El eslogan de uno de los anuncios de la campaña que mostraba un coche Volkswagen ante un enorme árbol decía: "Conservar lo verde es pensar en azul" y el anuncio expresaba "Un árbol de serie. Lo último en tecnología alemana”. Esta campaña, Think Blue, fue una de las costosas campañas publicitarias de la marca alemana anterior al escándalo del DieselGate (Jiménez Gómez, 2017, p. 5).

García Martín (2018) realiza un estudio centrado en analizar cinco ejes argumentales de los anuncios de coches en televisión. Estos ejes fueron: la banalización del término 'sostenible'; el coche como la "solución ambiental"; el menosprecio de otros medios de transporte; la trivialización de la ciudad, la complejidad urbana y la cosmética tecnológico-digital.

De la revisión realizada se ha podido comprobar que solamente cuatro trabajos internacionales se han centrado en la relación de la publicidad comercial de los automóviles y el medioambiente. Un estudio independiente realizado en Nueva Zelanda (Wilson, Maher, Thomson y Keall. 2008), otro realizado por una institución pública en Italia (Sco- 
pa et al., 2016), un informe de la European Environment Agency sobre la implementación de la Directiva 1999/94/EC (European Environment Agency, 2011) y otro publicado recientemente que analiza la publicidad de los automóviles en España y que, además, aporta un código de buenas prácticas publicitarias (Pedrós-Pérez, Martínez-Jiménez y Aparicio-Martínez, 2019).

Así, en Nueva Zelanda solamente el $4 \%$ de los anuncios de coches ofrecen los datos de emisiones de $\mathrm{CO}_{2}$ de los automóviles en la muestra analizada desde 2001 a 2005 (Wilson et al., 2008) ya que en este país no era obligatorio mostrar esta información. Se puede concluir que en aquellos países ajenos a la Unión Europea donde no existe obligación legal de informar de las emisiones de $\mathrm{CO}_{2}$, la industria no se ve incentivada.

En 2016 Scopa et al.(2016) utilizaron una muestra de 902 anuncios publicados en la revista más popular de coches de Italia para realizar su estudio. En este también se destaca la baja presencia de las emisiones de $\mathrm{CO}_{2}$ para un modelo específico de automóvil. Esto complica la posibilidad de los compradores de comparar las emisiones y consumos de diferentes opciones, lo cual representa un mayor empobrecimiento de la información ambiental sobre este tipo de vehículos.

En la actualidad, esta situación detectada por Scopa et al. (2016) se ve agravada por la gran disponibilidad que existe en el mercado de versiones diferentes de motorizaciones de automóviles para un mismo modelo (gasolina, diésel, hibrido, hibrido enchufable y $100 \%$ eléctrico). Por ejemplo, un anuncio de Opel Corsa en prensa del 23 de febrero del 2020 mostraba un intervalo de emisiones muy amplio (de 29 a 330 gramos $/ \mathrm{km}$ ), es decir, todo el espectro de $\mathrm{CO}_{2}$ de la gama ofertada de motores. Algunos estudios muestran que solo en los casos en los que se incluyen datos precisos de emisiones, el consumidor muestra una mayor confianza en la publicidad (Xie y Kronrod, 2012).

Finalmente, en un trabajo de reciente publicación (Pedrós-Pérez et al., 2019) los autores argumentan que la publicidad responsable, en el ámbito del automóvil, puede ser una herramienta para descarbonizar el transporte y luchar contra el cambio climático. El análisis del sector publicitario del automóvil en España en los años 2007, 2015 y 2016 detectó una baja presencia de buenas prácticas en el diseño de dichos anuncios. En concreto, mostró una gran ausencia de información relativa a los problemas energéticos relacionados con la movilidad, las emisiones y el cambio climático. Se verificó que en la publicidad de los coches existe un esfuerzo explícito de los fabricantes por ocultar las emisiones y el consumo de los distintos modelos. También se observó la ausencia de consejos referentes a una conducción eficiente de los vehículos motorizados o de un uso moderado de los mismos. Finalmente, y basado en este análisis, los autores proponen en esta investigación un detallado código de buenas prácticas para tener en cuenta por las empresas con el fin de alcanzar una publicidad responsable que incluye 28 medidas. Estas 28 medidas se clasificaron en siete categorías (Pedrós-Pérez et al. ,2019, pp. 327-328):

1) Información correcta de las emisiones y consumo de combustible.

2) Inclusión de información ambiental y consejos de buenas prácticas energéticas.

3) Información adecuada y responsable acerca de otras alternativas de movilidad (transporte público, peatón, etc.). 
4) Promocionar, con un mayor número de anuncios, los coches más eficientes y ligeros en lugar de la sobreexposición actual de los pesados todoterrenos, referenciados abreviadamente SUV.

5) Dejar de mostrar los coches en ubicaciones inadecuadas.

6) Dejar de promocionar maneras de conducción poco eco-friendly.

7) Cuidar el rol de la infancia en los anuncios de coches.

Como ejemplo concreto de este código se pueden citar dos recomendaciones literales de las 28 propuestas:

a) Los datos de emisiones y consumo deben incluirse y ser fácilmente visibles para todo tipo de vehículos. En los anuncios escritos estas informaciones deberían figurar a un tamaño y tipo de letra, al menos, similar al del resto de características publicadas y, en ningún caso, usar letras inferiores a 1,2 mm de altura.

b) La publicidad de los automóviles podría recomendar compartir el coche para los desplazamientos habituales. Se podría incluir alguna frase como "Comparte tu vehículo, ahorraremos combustible y contaminaremos menos".

\section{Observatorios y redes sociales}

A continuación, se abordan los denominados observatorios de la publicidad. Estos observatorios pueden monitorizar los anuncios en detalle, centrándose en aspectos concretos de interés. Este seguimiento puede realizarse desde sectores independientes por medio de un panel neutral de expertos o puede incluir representantes de la industria y/o de las empresas de anunciantes. Estos observatorios analizan los anuncios y las campañas y confeccionan y en consecuencia difunden informes sobre estas. En ocasiones, los observatorios recomiendan algunas modificaciones en las campañas o piden directamente la retirada de ciertos anuncios impresos o en formato audiovisual por sus contenidos inapropiados.

Hay una gran carencia de observatorios que relacionen la publicidad empresarial con la movilidad sostenible, el ahorro energético y/o el cambio climático. Estas carencias han sido tratadas por los autores de este artículo en sus investigaciones desde hace al menos 15 años. En el año 2005, en un estudio inicial, se planteó la necesidad de realizar un observatorio de la publicidad de la movilidad sostenible (Pedrós-Pérez, 2005). El Observatorio de la Publicidad de la Movilidad Sostenible se presentó como una iniciativa que se proponía ser un canal de comunicación, elemento de intervención, foro de debate y reflexión sobre los contenidos de la publicidad que hacen referencia a los diferentes aspectos sociales, educativos, ambientales, culturales y económicos de las variadas formas de movilidad. Esta propuesta inicial se debía a que, de la misma manera que existen observatorios de la publicidad relacionados con temas de género (OAPM, 2020), un tema de tanta trascendencia para la calidad de vida de la población y para la preservación del medio ambiente urbano y natural, como es el de la movilidad, necesitaba de un observatorio específico.

En otros estudios posteriores y mediante el uso de la etiqueta «Observatorio de la Publicidad» y en el blog OtraCórdobaesPosible, se ha realizado un amplio análisis del material publicitario existente (Pedrós-Pérez, 2018). Otra ventaja que aportan los materiales derivados 
del análisis de la publicidad de la movilidad es la vinculación de los problemas del entorno urbano con el medioambiente ya que investigaciones realizadas por diferentes autores (Megías Delgado, Baldallo González y Maraver López, 2018) han detectado que para diversos colectivos el medioambiente solo se identifica con el medio natural.

Otro argumento más que justifica la necesidad de estos observatorios estriba en el enfoque a veces diametralmente opuesto de las campañas de las instituciones públicas y las de las empresas de automóviles.

Mientras que las administraciones públicas destinan cada vez más recursos a promover cambios de hábitos sociales para hacer frente a los grandes problemas ambientales generados por un modelo de movilidad dominado por el vehículo motorizado privado, la dependencia y el deseo de posesión de este objeto se potencian incesantemente en los medios de comunicación, especialmente a través de la publicidad televisiva. Miles de millones de euros se destinan anualmente, en toda Europa, a la promoción del uso del coche, generando un imaginario donde este pasa a representar ciertos valores simbólicos y expresivos, como la identidad, la imagen o el prestigio social del usuario.

Si en el año 2016 el sector de la distribución y restauración fue el que destinó un mayor volumen de inversión a publicidad, en 2017 el de la automoción le quitó el puesto (Sánchez-Revilla, 2018). La automoción incrementó un 7,6\% su inversión publicitaria; en concreto, invirtió 505,6 millones de euros, lo que representa un 7,6\% más de lo que se gastó el año anterior. Además, este informe apunta que Volkswagen fue la cuarta compañía que más invirtió en publicidad y que un total de seis firmas de automóviles estaban en la lista de las 20 que más gasto realizaron en anuncios publicitarios en 2017.

Para acabar este apartado hay que destacar un proyecto que bien llevado podría tener un largo recorrido. En octubre del 2019, ECODES ha diseñado un Observatorio de Publicidad responsable frente al cambio climático (ECODES, 2020). Los objetivos específicos de este observatorio son: a) Analizar el modo en que la comunicación comercial del sector energético, transporte, limpieza del hogar y tiempo libre influye en la adaptación y mitigación al cambio climático; b) Difundir los resultados del análisis y del código de autorregulación sobre argumentos ambientales en comunicaciones comerciales a la población en general.

Por otro lado, algunos autores (Gal-Tzur, Grant-Muller, Kuflik, Minkov, Nocera y Shoor 2014) han tratado el uso de las redes sociales para conseguir objetivos de mitigación en las políticas de transporte y, sorprendentemente, no abordan entre sus elementos de análisis la publicidad de los automóviles en estos social media.

En un estudio realizado recientemente en España (Pedrós-Pérez et al., 2019), estos autores partieron como hipótesis inicial de que, dada la cantidad de espacio disponible en las websites publicitarias de los automóviles, las empresas de coches ofertarían a los consumidores muchos más aspectos ambientales de sus productos que en los reducidos espacios de la prensa escrita y de otros medios físicos. El análisis realizado para la publicidad de 36 modelos (2015) y 46 modelos (2016) en sus websites concluye que la disponibilidad de mucho espacio en estas páginas virtuales no motiva a las empresas a la inclusión de información ambiental, sobre el cambio climático o sobre emisiones de $\mathrm{CO}_{2}$, siendo la presencia de esta muy marginal y en muy pocos casos.

Por tanto, una propuesta para el futuro sería determinar de una forma más amplia qué información o propuestas sobre movilidad sos- 
tenible y adaptación o mitigación del cambio climático ofrece la publicidad de las empresas de automóviles en sus websites, Facebook, Instagram y en Twitter.

En este sentido los autores de este artículo han detectado en una primera aproximación que mucha de la información que publican los medios periodísticos sobre motor en sus websites y redes sociales está más cercana a la publicidad que al análisis independiente. Basta por ejemplo hacer una visita a la Web de Motor del diario El País (El País Motor, 2020) para encontrar artículos que son casi indistinguibles de la publicidad.

\section{Metodología del artículo}

Como se ha visto en los antecedentes, las investigaciones sobre publicidad y movilidad son escasas y se han centrado en el campo del automóvil. En este trabajo se ha optado por combinar una aproximación cualitativa con algunos análisis cuantitativos de ciertos aspectos específicos (Fowler III y Close, 2012) debido al hecho de que algunos ítems son más fáciles de cuantificar que otros. Siguiendo la metodología aplicada por Atkinson y Kim (2015), se ha implementado un análisis cuantitativo estableciendo la frecuencia y variedad de los mensajes de la publicidad con los ítems que se describen en secciones posteriores de este trabajo.

Este análisis se ha basado en el material recopilado por los autores en más de veinte años donde aparece la bicicleta bien como elemento contextual bien como producto. Se ha recurrido también a la revista Ciclosfera ${ }^{4}$ para analizar el segmento de la publicidad de las bicicletas en papel impreso. Ciclosfera es la única revista comercial en España donde predomina la bicicleta como medio de transporte urbano. El resto de las revistas que se publican en España están enfocadas a la bicicleta deportiva.

Se plantea como objetivo del artículo analizar la publicidad comercial e institucional donde aparezca la bicicleta. Esta publicidad se aborda en diferentes campos seleccionados por los autores: publicidad de diversos productos que usan la bicicleta como elemento de acompañamiento, la bicicleta en anuncios de coches, campañas institucionales y finalmente publicidad de las empresas de bicicletas.

A continuación se plantean los objetivos específicos del estudio. Evaluar el papel de la bicicleta en los anuncios de diversos productos ajenos a la movilidad y en los anuncios de coches. Analizar las campañas institucionales de promoción de la bicicleta como vehículo de transporte, detectando sus puntos fuertes y débiles. Identificar si la salud es un elemento que se destaca como forma de movilidad activa. Determinar si se muestra preocupación ambiental en la publicidad de las bicicletas. Analizar si el cambio climático tanto en sus formas de mitigación como adaptación está presente acompañando a los modelos, declarando por ejemplo que es un vehículo cero emisiones. Determinar si la Smart City se relaciona con la bicicleta, especialmente con las bicicletas eléctricas, mayormente conocidas como e-bikes. En resumen, detectar tanto buenas como malas prácticas.

La selección e interpretación de los anuncios fue condicionada por los objetivos del estudio. La publicidad puede ser considerada como un discurso tanto textual como gráfico. La interpretación de estos discursos y su evaluación en términos de si contribuyen a una promoción 


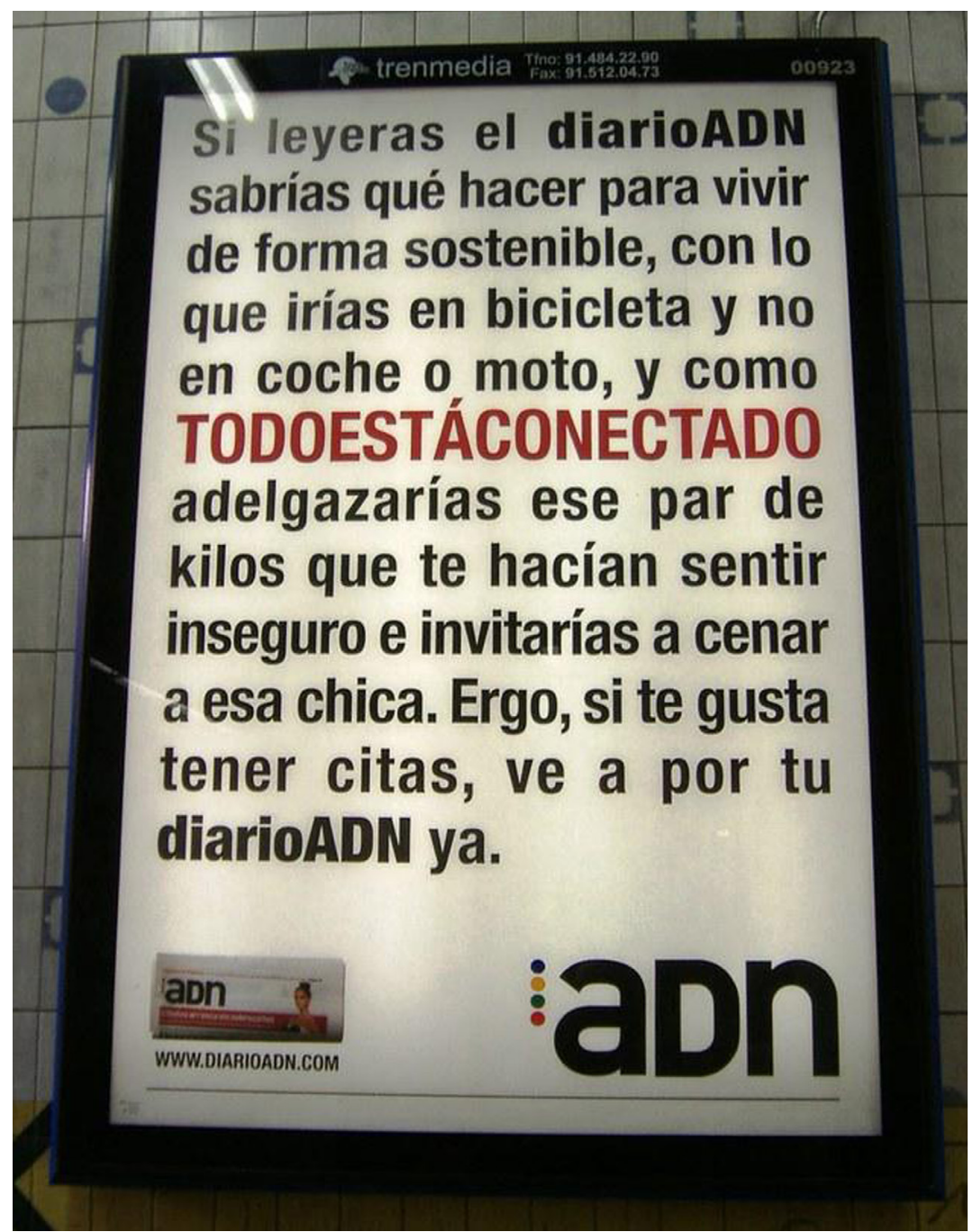

adecuada de la movilidad activa en bicicleta alejada del denominado "estigma" (Aldred, 2013) constituyen parte importante de esta investigación. Como señala Aldred (2013) la elección del medio de locomoción no está efectivamente restringida a un mero cálculo material basado en criterios como la rapidez, el coste, la comodidad o la seguridad, sino que además está influenciada por las formas culturales y las escalas de valores propias del individuo y de la sociedad en la que vive. De hecho, en grandes sectores de la población española y de los medios de comunicación la bicicleta sigue teniendo un "estigma" de medio de transporte de baja categoría o, en todo caso, propio de jóvenes deportivos o ecologistas. Romper ese estigma es un objetivo imprescindible de cualquier política de promoción de la bicicleta con pretensiones realmente transformadoras (Aldred, 2013).

El análisis fue realizado por investigadores expertos en movilidad sostenible y que participan en el seminario "Respuestas desde la Comunicación y la Educación al Cambio Climático" (CENEAM, 2018). El último seminario tuvo lugar en Navarra en octubre del 2019.
Figura 1. Publicidad del Diario gratuito ADN. Fuente: valla publicitaria del Metro de Madrid. Año 2007.
Resultados

\section{Publicidad de diversos productos que usan la bicicleta como reclamo}

En primer lugar, se aborda la publicidad en diversos productos que usan la bicicleta como elemento contextual. Son numeroso los anuncios de este tipo recopilados por los autores y que abarcan diferentes áreas: prensa gratuita, medicamentos, vinos, empresas energéticas, alimentos, bebidas azucaradas, empresas de servicios financieros, marcas de ropa, bancos, etc. Un total de 44 anuncios diferentes componen la muestra.

Los sectores que más recurren a la bicicleta son: bancos y empresas de seguros $(32 \%)$, alimentación $(18 \%)$, y medios de comunicación $(14 \%)$. En el ámbito de los productos farmacéuticos solamente un $7 \%$ de los anuncios.

En cuanto a las argumentaciones visuales o textuales: aparecen mayoritariamente ciclistas urbanos en los anuncios $(64 \%)$, siendo importante que un $50 \%$ la presente como medio de transporte, otros anuncios la asocian a la diversión (36\%), mejor comunicación entre las personas $(25 \%)$ y elemento saludable $(23 \%)$. Destaca negativamente que solamente un $14 \%$ la vincula al medioambiente y un porcentaje bajísimo $(7 \%)$ con el cambio climático. Las malas prácticas detectadas representan escasamente un $7 \%$. Estas se han centrado en potenciar un sentimiento de superioridad entre los que se desplazan en coche 
o motocicleta respecto de usuarios de la bicicleta (dos anuncios) y otra en considerarla como un vehículo para jubilados que son los que tienen más tiempo libre.

A continuación se analizan con más detalle y de forma cualitativa algunos de ellos.

Un anuncio paradigmático que refleja un buen argumentario es el que utilizó el desaparecido periódico gratuito $A D N$ y con el que llenó muchas vallas publicitarias del metro de Madrid en 2007 (Figura 1): "Si leyeras el diario $A D N$ sabrías qué hacer para vivir de forma sostenible, con lo que irías en bicicleta y no en coche o en moto, y como todo está conectado adelgazarías ese par de kilos que te hacían sentir inseguro e invitarías a cenar a esa chica". En el texto del anuncio se abordan muchos elementos interesantes: cambio climático, salud, movilidad activa, relaciones entre las personas, etc.

Este anuncio tan explícito puede vincularse a la enorme presencia mediática del documental de Al Gore a mediados del 2007, con lo cual la sostenibilidad irrumpe en los medios de comunicación con fuerza en este año, como detectan algunos autores (Jiménez Gómez y Martín-Sosa, 2018). Lo anterior y la presentación de la Estrategia Estatal de Cambio Climático hacen que el calentamiento global y las emisiones aparezcan con fuerza en la publicidad empresarial a mediados del año 2007 (Pedrós-Pérez y Martínez-Jiménez, 2010).

También la publicidad de ciertos medicamentos empleará a personas desplazándose en bicicleta como sinónimo de vida saludable, es el caso de Supradyn activo "que te recarga de energía cada mañana" (Figura 2). En este anuncio como buena práctica la supuesta madre y el hijo van vestidos con ropa que no es deportiva atravesando un viario que pasa por un parque. Es un anuncio vinculado a la anteriormente mencionada "movilidad activa" (Haufe et al., 2016).

Otro ejemplo de buena práctica es la bicicleta usada en la publicidad de un vino de la marca Martin Codax. Frente a otras ocasiones donde se considera al que usa la bicicleta como alguien marginal en este caso la tenemos asociada a una botella de vino de buen etiquetado (Pedrós-Pérez, 2014). Es de aquellos pocos anuncios donde se atreven a asociar la bicicleta con un producto de cierta categoría. A pesar del citado anteriormente "estigma" (Aldred, 2013) impuesto social y publicitariamente a los que no usan el coche, se encuentran algunos lugares, Cambridge (Carse et al., 2013), donde estudios cuantitativos que tienen como variable la estratificación socioeconómica de los usuarios, viajar en coche no está asociado a una posición económica alta. En este estudio fue encontrada una relación inversa con la posición económica. Hay una mayor tasa de uso de la bicicleta entre los de alta posición económica (30\%) comparada con los de baja $(23 \%)$.

Los molinos eólicos en el sector energético o el coche eléctrico en el de la automoción son un referente icónico de la producción y consumo sin impactos medioambientales. Así, la fuerza semántica de los 


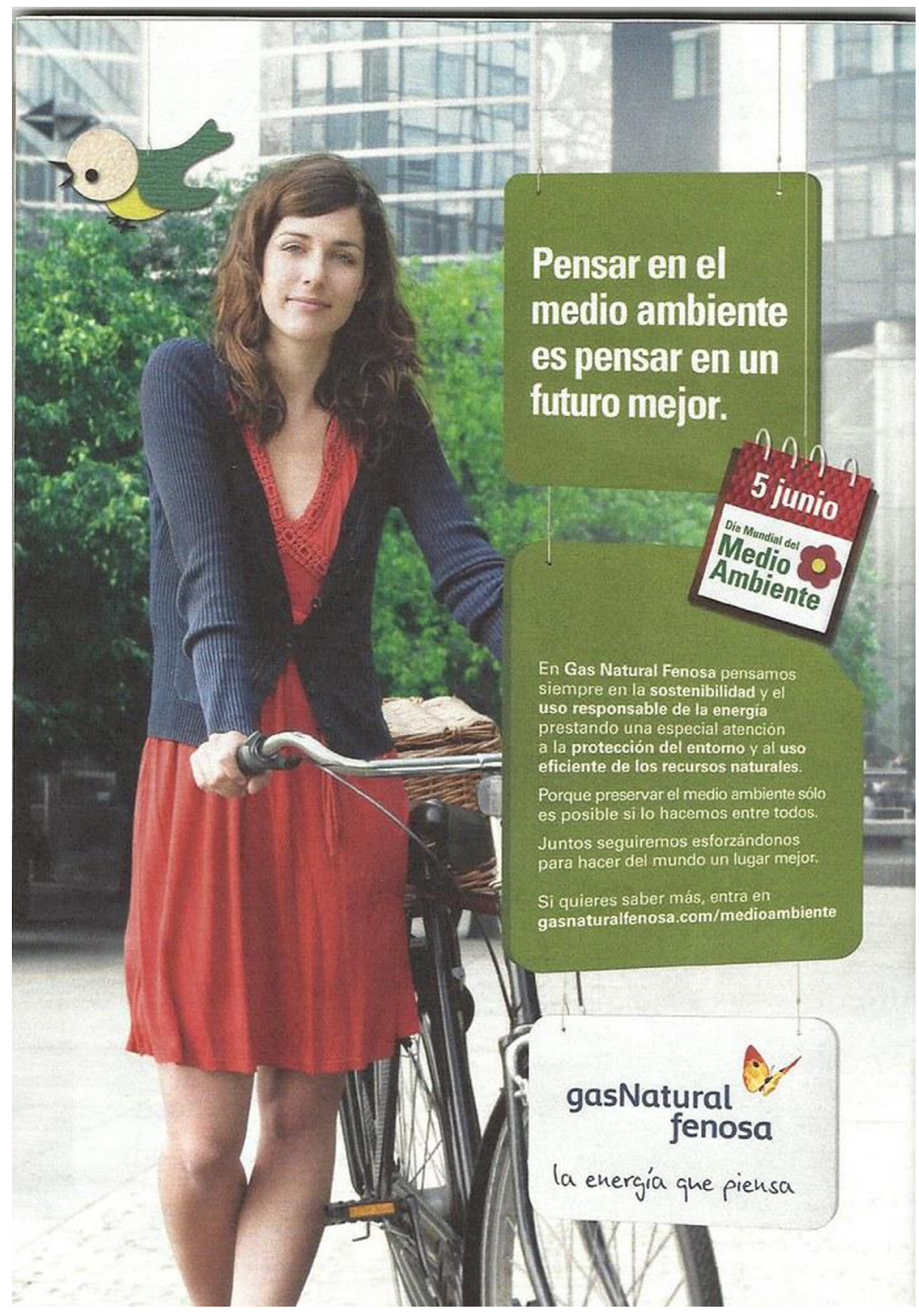

Figura 3. Publicidad de Gas Natural Fenosa con motivo del 5 de junio. Fuente: Diario El País. Año 2014 aerogeneradores ha extendido su uso en multitud de materiales gráficos de empresas y entidades públicas pertenecientes a diversos sectores (Jiménez-Gómez, 2017). Un papel similar está aportando la bicicleta en los anuncios de empresas energéticas como es el caso de Gas Natural Fenosa (Figura 3), que usa la bicicleta en su publicidad para conmemorar el día 5 de junio, día mundial del Medio Ambiente. En muchas ocasiones esta efeméride se asocia con la naturaleza, con parques naturales, senderismo, etc., mientras el medioambiente urbano que es en el que transcurre la mayor parte de la vida de los seres humanos no se menciona. En este anuncio de la empresa Gas Natural ocurre lo contrario, se muestra un contexto eminentemente urbano con grandes edificios y la bicicleta es una del tipo para desplazarse cómodamente por la ciudad. El slogan es: "Pensar en el medio ambiente es pensar en un futuro mejor", con lo cual la bicicleta se asocia con el vehículo del futuro "para hacer del mundo un lugar mejor".

Otra energética, en este caso la eléctrica Endesa, usa la bicicleta y un paisaje de molinos eólicos para ilustrar su compromiso con un mundo más sostenible como empresa patrocinadora de la Cumbre del Clima de Madrid, la COP 25 (Figura 4). El texto que acompaña el anuncio es: "¿Tu energía te lleva a un mundo más sostenible? Confía en una compañía que lleva la energía de la naturaleza a 10 millones de Hogares. What's your power?". Se muestra un entorno no urbano y una bicicleta sin guardabarros para moverse por el campo y por el perfil de la imagen parece probablemente del tipo e-bike. En este caso no es un adulto el que maneja el vehículo sino un adolescente. El anuncio podría evaluarse como un caso claro del denominado greenwashing (Nyilasy et al., 2014), pues Endesa posee desde hace muchas décadas varias centrales térmicas de carbón para producir electricidad, alguna de ellas como la de "As Pontes" de gran tamaño, aunque haya anunciado su intención de cerrarlas (EFE, 2019).

Otro hecho que confirma el greenwashing de Endesa es el comportamiento antirrenovables con el Ayuntamiento de Madrid (Agencias, 2018):

El Tribunal Administrativo de Contratación Pública ha desestimado los recursos — presentados por Gas Natural, Endesa e Iberdrola- contra los pliegos para el suministro de energía eléctrica renovable de edificios municipales de Madrid. Dicho acuerdo incorpora como criterio de solvencia técnica la certificación, emitida por la Comisión Nacional de los Mercados y la Competencia (CNMC), de que la energía comercializada deba ser de origen $100 \%$ renovable (etiqueta $\mathrm{A}$ ). 
La sostenibilidad, y toda la retórica ambiental asociada a este concepto, ha acabado por instalarse casi en cualquier discurso publicitario. Precisamente por la dificultad para delimitar conceptualmente el sentido y el alcance de lo sostenible, cualquiera puede arrogarse el término sin más problemas. Lo paradójico es que lo anuncie dicha multinacional Endesa, sin que quede muy claro cómo produce energía eléctrica de forma sostenible.

Se recurre a anuncios y campañas publicitarias en las que aparece, explícitamente o mediante lenguajes retóricos y figurados, un pretendido mensaje de protección del medio ambiente que no se corresponde con una realidad subyacente escondida tras esa amable imagen proyectada de la bicicleta. El reclamo de lo "sostenible" en este tipo de comunicación publicitaria ha logrado producir en los consumidores lo que algunos autores denominan “ecofatiga” (Jiménez Gómez, 2017).

\section{La bicicleta en la publicidad de los coches}

Es destacable que de la base de datos de publicidad de coches que se ha utilizado en este estudio, y que consta de 592 anuncios, solamente en 9 de ellos aparezca la bicicleta. No obstante, debido a sus argumentaciones, algunos de estos anuncios se han convertido en virales sobre todo entre los defensores de la movilidad sostenible. Además, debido a la gran inversión publicitaria, que se ha señalado anteriormente, que realizan las marcas de coches en los medios de comunicación, cualquier mensaje publicitario que lanzan posee una potencia comunicativa muy grande. En consecuencia, cualquier campaña de la Asociación Española de Fabricantes de Automóviles y Camiones(ANFAC) tiene un eco tremendo en los medios.

Hay que tener en cuenta que, aun siendo muy pocos anuncios, el $78 \%$ de estos han sido evaluados como malas prácticas publicitarias desde la visión de la movilidad sostenible. Cuantificando las principales argumentaciones que presentan un porcentaje elevado: admiración por el coche (44\%), asociar la bicicleta al riesgo (33\%), la bicicleta es un vehículo para la infancia (22\%) y es un vehículo que debe circular por las aceras (11\%). El 44\% de los anuncios con bicicleta eran de los llamados vehículos todo-terreno (SUV). No se ha querido aprovechar por las marcas la elevada capacidad de los maleteros de estos modelos SUV para sugerir la posibilidad de usarlos como forma de intermodalidad con la bicicleta. De hecho, la posibilidad de la intermodalidad bicicleta-coche no se recoge en ningún anuncio de la muestra.

Se analizan a continuación con más detalle varios ejemplos concretos. El anuncio del Audi A3 con la bicicleta bajando peligrosamente por una cuesta llevando a un bebe atrás y sin conductor (Figura 5). El texto del anuncio es sumamente indicativo: "Hay sensaciones que no desearás volver a experimentar nunca. Como la de perder el control. Conduciendo un Audi A3 con tracción integral quattro experimentarás justo lo opuesto". El mensaje asocia el peligro a montar en bicicleta. Fo- 

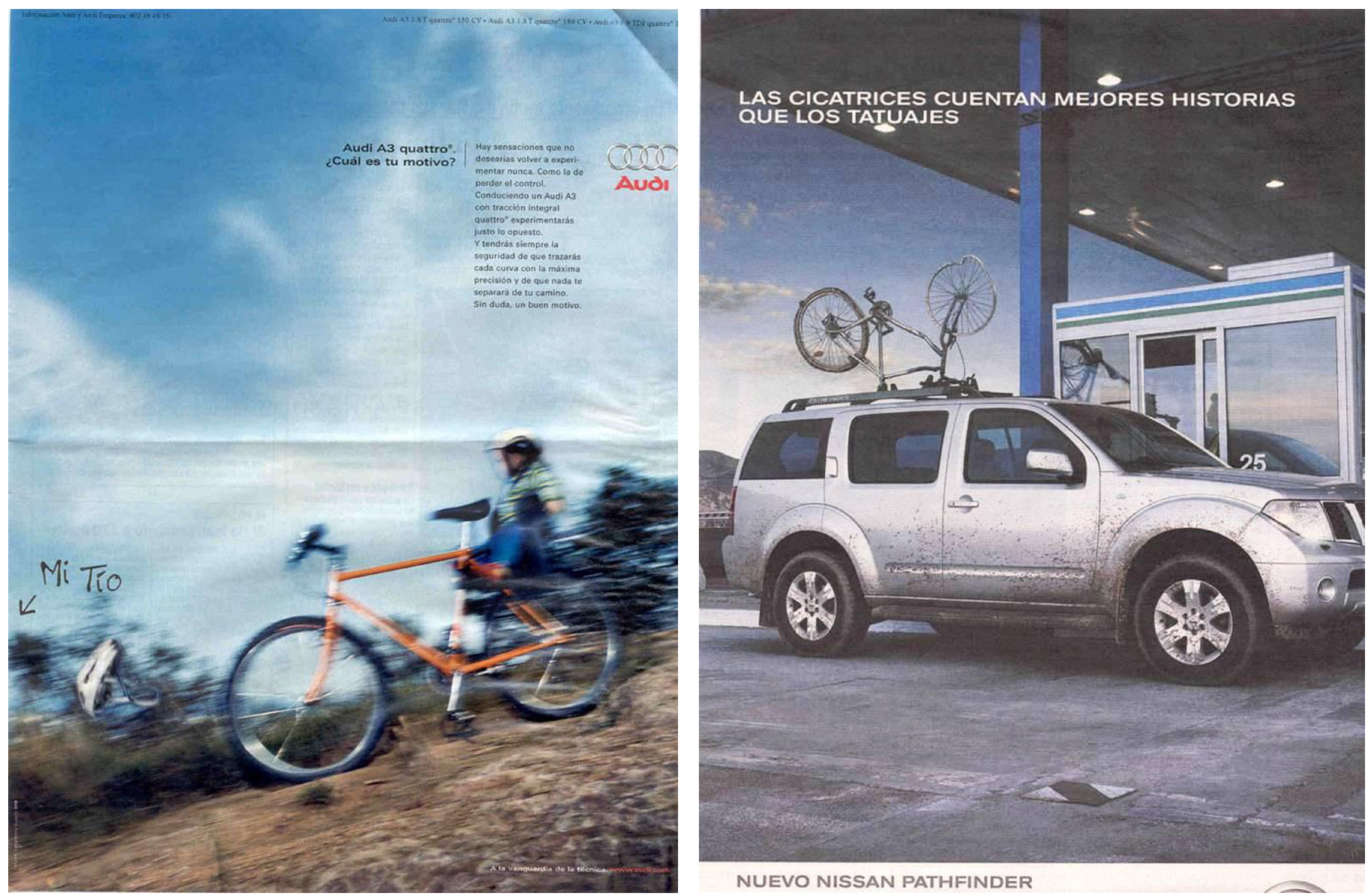

NUEVO NISSAN PATHFINDER

$\approx$

Figura 5 [izquierda]. Publicidad de Marca de Coches Audi. Fuente: revista Fotogramas. Año 2001 . Figura 6 [derecha]. Nuevo Nissan Pathfinder. Fuente: País Semanal. Año 2007.

Figura 7. Seat Alhambra. La bicicleta es un juguete para niños. Fuente: Website de Seat. Mayo 2016. menta la idea de que desplazarse en bicicleta es algo arriesgado, además de practicado por irresponsables. Lo que está demostrado es que el peligro para los ciclistas proviene del comportamiento incívico y de la velocidad excesiva de muchos automovilistas.

En la publicidad del todoterreno "Nuevo Nissan Pathfinder" (Figura 6) se argumenta de forma similar, se enfrenta el vehículo bicicleta totalmente deformado por un accidente y relegado a la baca del coche vs. el sólido y seguro todoterreno.

En otros anuncios de coche en prensa y televisión se muestra la bicicleta como un medio de transporte asociado a la infancia; es el ejemplo

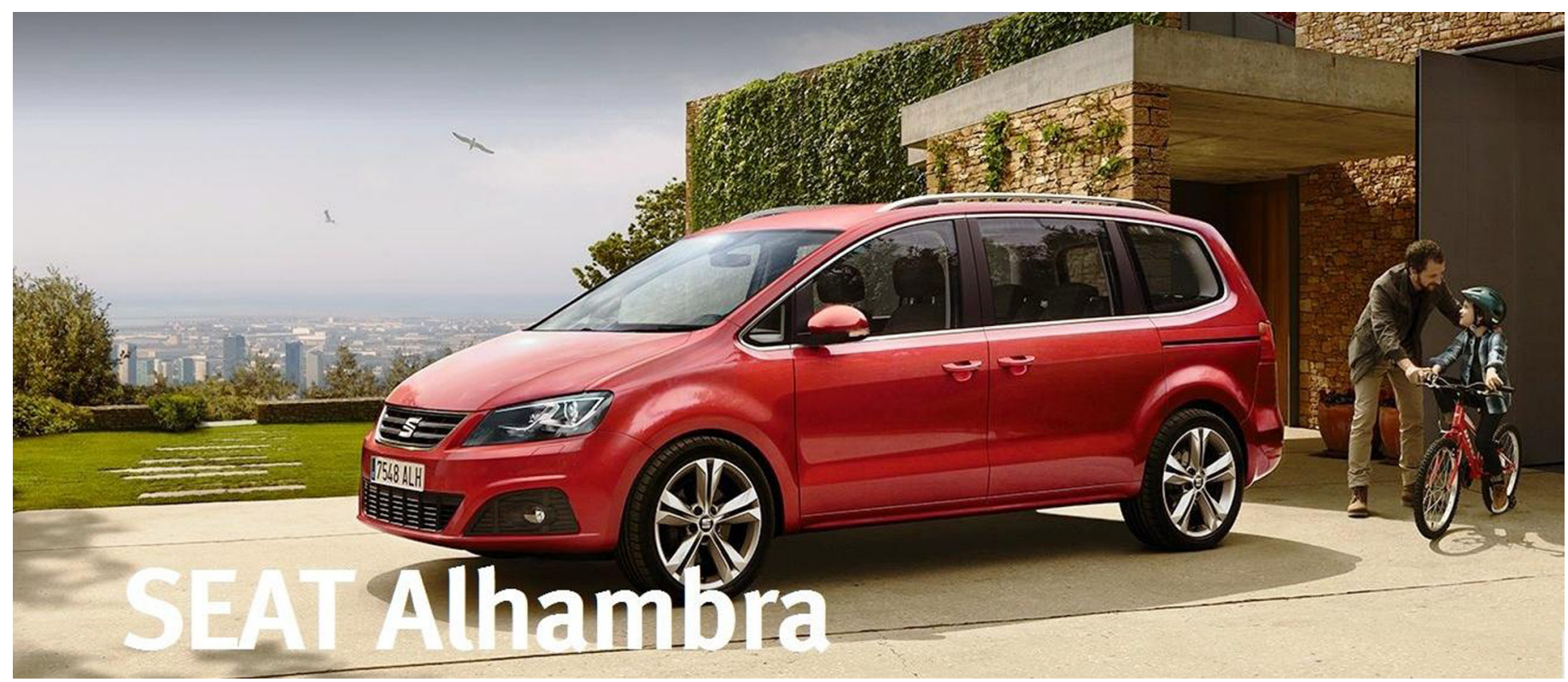




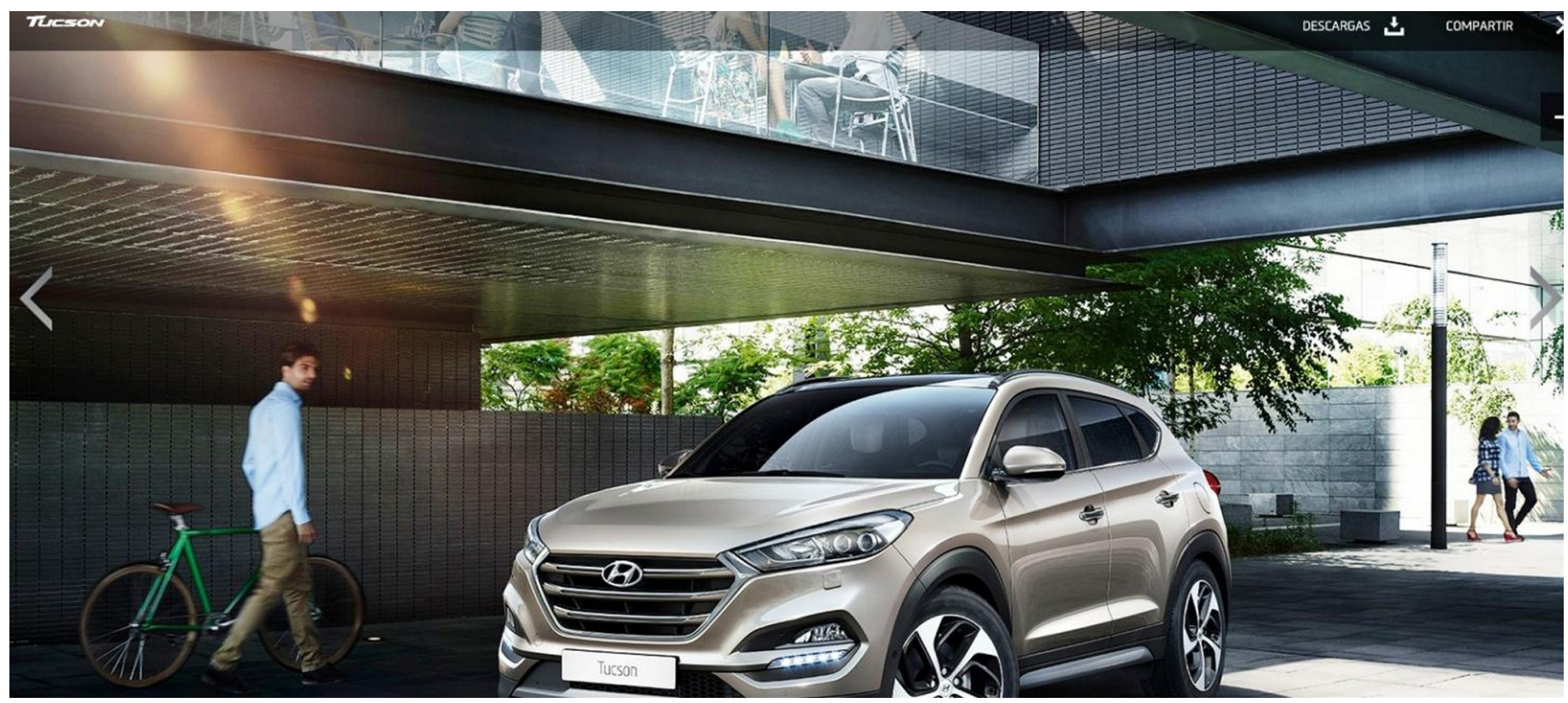

concreto del anuncio del Seat Alhambra (Figura 7). En otro anuncio de "Hyundai Tucson Todoterreno"el ciclista se baja de la bicicleta y camina para admirar con detenimiento la superioridad del vehículo SUV que se desplaza en un medio urbano (Figura 8).

En otros la bicicleta se muestra como algo mitad elemento decorativo "vintage" y mitad objeto asociado a la infancia(Anuncio Audi A3, Figura 9). El slogan es bastante poco responsable ambientalmente: "después de todo no has cambiado tanto", indicando el paso de la bicicleta a un vehículo motorizado contaminante.

Podría resumirse que este tipo de publicidad de coches presenta el automóvil como el modo de transporte normativo y habitual, infravalorando o incluso despreciando a la bicicleta como vehículo. Ese mismo tipo de minusvaloraciones aparecen en algunos anuncios de coches para el transporte público o el desplazamiento andando como han descrito algunos autores (García Martín, 2018; Pedrós-Pérez et al., 2019).

Como se señalaba más arriba, no se han detectado tampoco anuncios de automóviles donde se fomente la intermodalidad bicicleta coche. Esta es una solución eficaz al transporte en unas ciudades con un urbanismo difuso donde son muy frecuentes los desplazamientos motorizados desde viviendas en barrios dormitorio hasta aparcamientos disuasorios (Marqués Sillero, 2017, p. 96).En estas ubicaciones de destino sería ideal poder sacar del automóvil la bicicleta plegable para acabar el trayecto.

Concluyendo, la bicicleta es percibida por algunas marcas de automóviles con un alto potencial como vehículo de transporte, de ahí que la ignoren en el $99 \%$ de su publicidad. Además, en base a esto en algunos anuncios de coches se presenta la bicicleta con una imagen que contribuye a colocarla en una posición incómoda, enfatizando los riesgos en su desplazamiento, mostrándola como un objeto decorativo, como un vehículo apropiado para
Figura 8. Hyundai Tucson Todoterreno. Imagen procedente del Website de la marca. Mayo de 2016
Figura 9. Modelo Audi A3. La bicicleta como elemento decorativo. Fuente: $E l$ País Semanal, 2010.

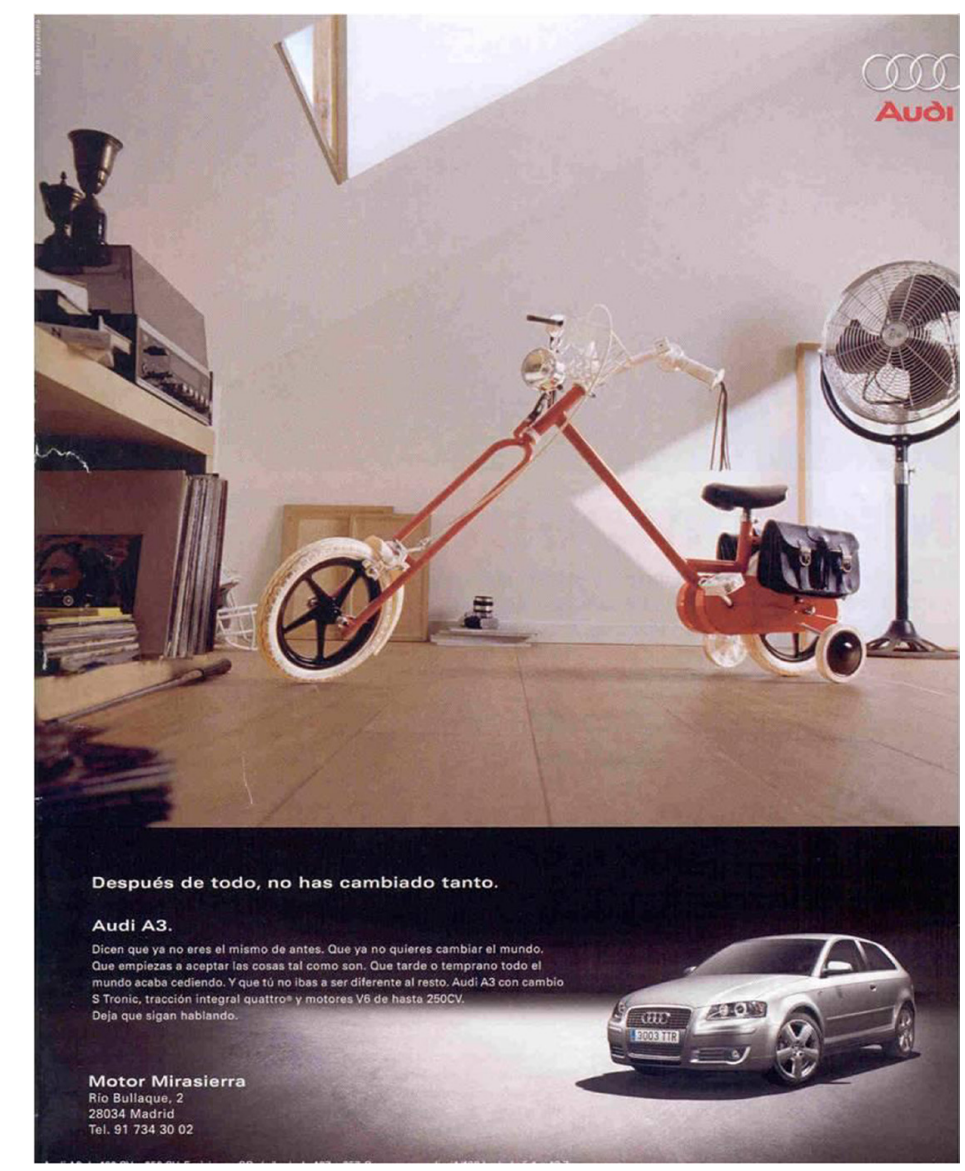


Figura 10. Publicidad Institucional. Bicicleta del cantón de Ginebra en Suiza. Año 2009

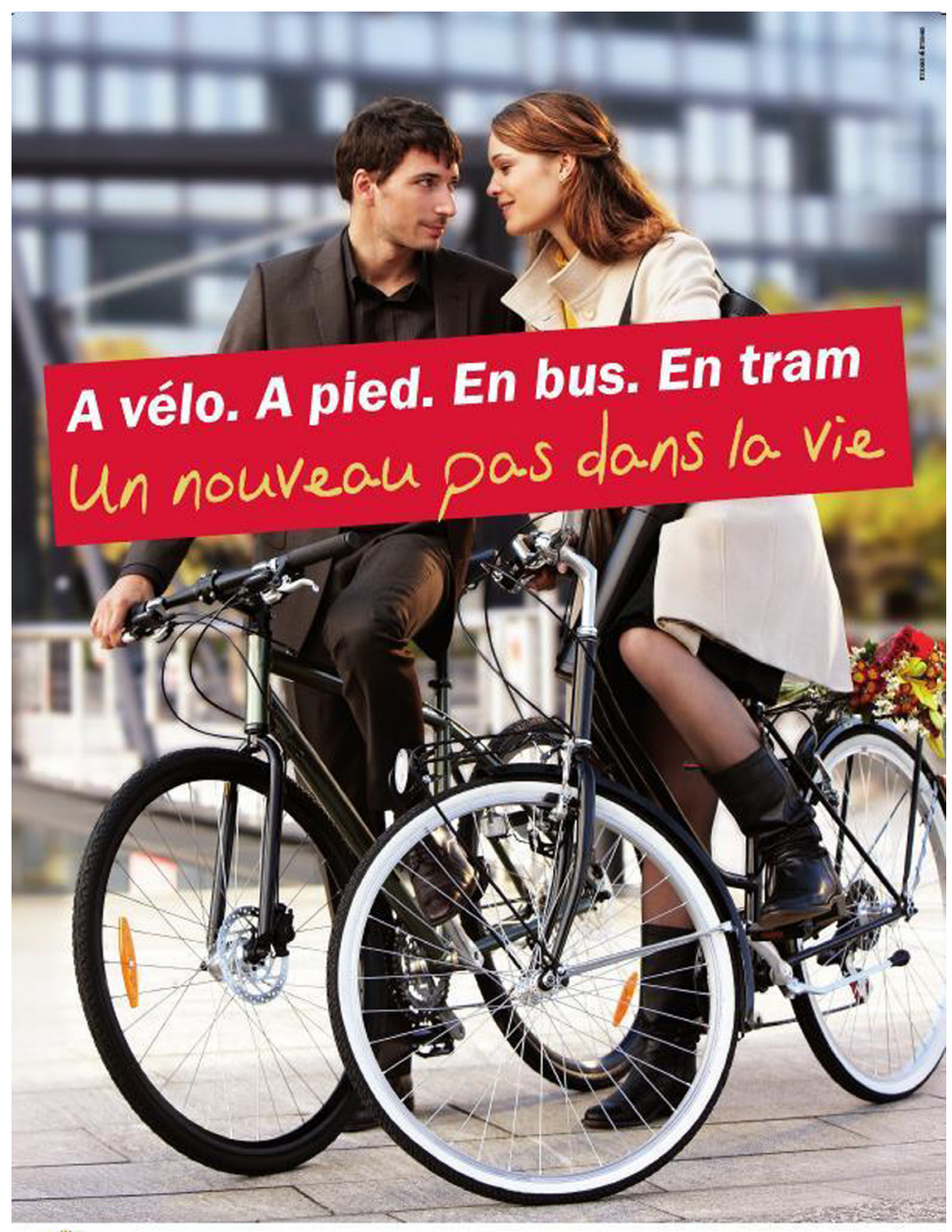

www.ge.ch/mobilite

L'air de rien changeons l'air! niños que conseguirán su objetivo de adultos cuando empiecen a desplazarse en coche, etc.

\section{Publicidad institucional}

El sector de la Administración a través de la publicidad institucional empieza tímidamente a promocionar la bicicleta como medio de transporte urbano. A este sector se unen también las campañas de promoción de organizaciones probici de la sociedad civil. En este apartado se analizan ambos sectores.

La muestra cubre 20 campañas institucionales. Se han analizado diferentes ítems. Un $25 \%$ de las campañas mezclan diferentes modos de transporte, colocando a la bicicleta como aliada, por ejemplo, del transporte público, hacen referencia a entornos urbanos en un 30\%, la bicicleta se presenta como medio de desplazamiento en la ciudad en un $55 \%$ y finalmente puede ser también un objeto vintage-romántico (25\%).

Es destacable qué beneficios importantes de este tipo de movilidad son infrarrepresentados: salud (15\%), ahorro en combustible (5\%) y calidad del aire $(5 \%)$.

Las malas prácticas detectadas representan un 25\%. Como ejemplos de estas, la organización del Día de la Bicicleta en la ciudad, en ocasiones coincidiendo con la Semana Europea de la Movilidad, sin aportar en la campaña ningún elemento ambiental o de movilidad activa, simplemente como un motivo de diversión. Otra mala práctica en campañas institucionales ha sido mostrar también la bicicleta como algo propio de la infancia. A continuación, se analizan con detalle varios casos concretos de campañas de la administración.

Se presenta una campaña de publicidad institucional del cantón de Ginebra en Suiza donde se promociona al mismo nivel los medios de transporte sostenibles: caminar, bicicleta, autobús y tren (Figura 10). Es un ejemplo de una buena práctica publicitaria pues muestra la bicicleta de una forma inclusiva. Muchas campañas de promoción del transporte público olvidan al caminante y a la bicicleta que son sus aliados naturales. Por otra parte, la bicicleta está contextualizada adecuadamente alejada del "estigma" (Aldred, 2013), mostrando un entorno urbano y gente elegante. Esta campaña la hicieron los suizos hace más de diez años, lo que muestra una idea del compromiso existente en este país hace ya más de una década.

Otra buena práctica publicitaria es la del ayuntamiento de Valladolid y su sistema de bicicletas públicas denominado "VallaBici" (Figura 11) con el siguiente slogan: "Súmate al efectocicleta. Todo cuerpo subido a una bicicleta experimenta el placer de tener solo ventajas: Limpia y respetuosa, enamora, cómodo/a, ahorra, sanote, sanota". La usuaria del anuncio es una persona joven que se desplaza vestida informalmente por un entorno urbano y claramente se promociona el mensaje de la bicicleta como medio de 

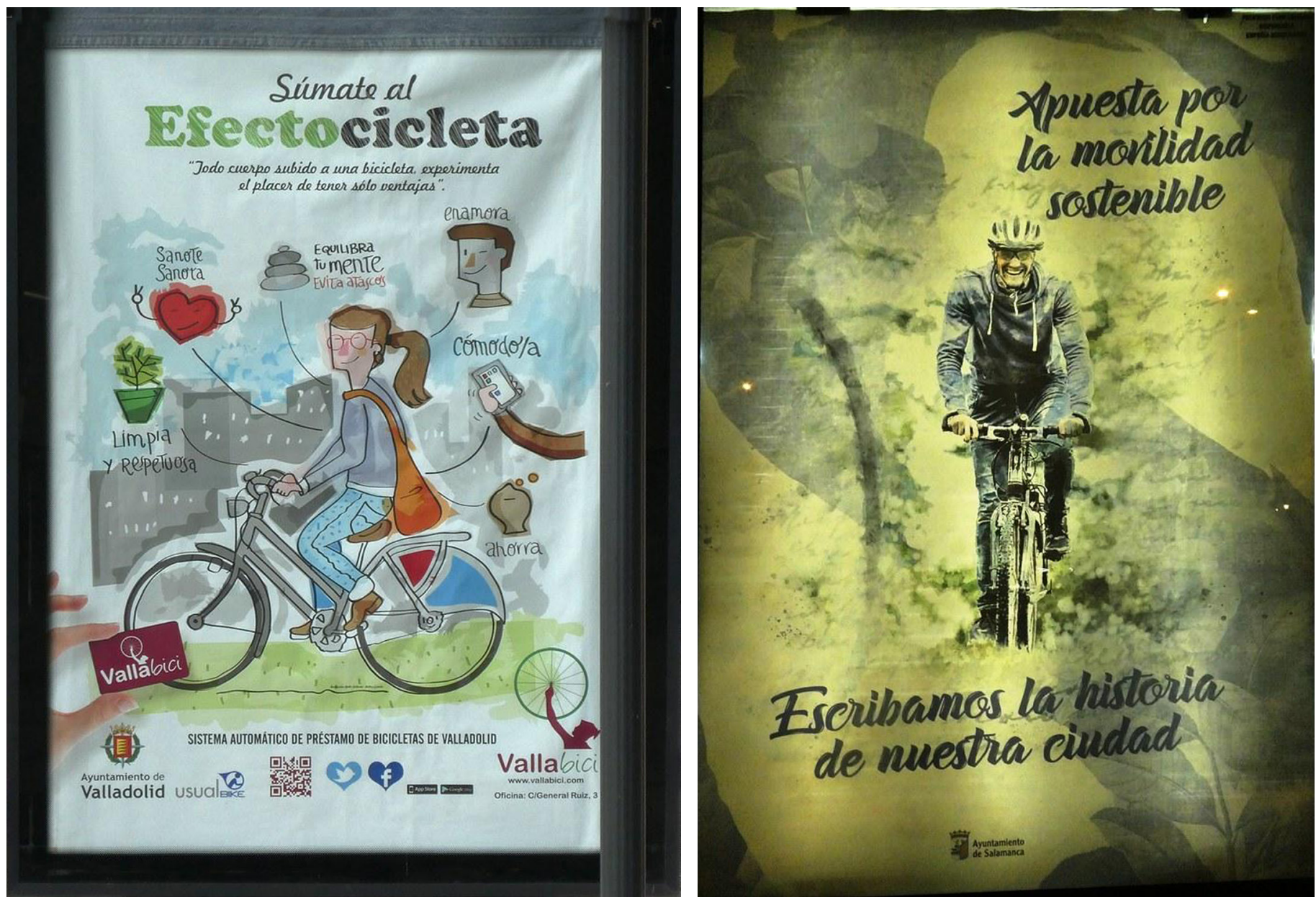

transporte habitual y cotidiano y con atributos ligados al medio ambiente, la salud y la comunicación intrapersonal.

Por el contrario, como mala práctica de publicidad institucional cabe señalar la correspondiente al Ayuntamiento de Salamanca en el verano del 2019 (Figura 12). El slogan es "Apuesta por la Movilidad Sostenible. Escribamos la historia de nuestra ciudad". Se ilustra la movilidad sostenible con un usuario vestido integralmente de deporte y en un contexto que parece una prueba de ciclismo por el campo. De nuevo una institución pública comete el error de asociar el transporte en bicicleta (movilidad sostenible) con una práctica deportiva y de riesgo, va con casco.

También se emplea mucho la imagen de la bicicleta en la propaganda institucional vinculada al turismo, asociando este vehículo con el descubrimiento de nuevos sitios y la relajación del tiempo sin prisas. Se presenta una campaña de la Consejería de Turismo de la Junta de Andalucía (Figura 13) que puede ser justificada como una buena práctica pues aparece una mujer vestida de forma elegante y manejando una bicicleta urbana. Otras campañas también promocionan el turismo con imágenes de bicicletas y se han encontrado de la ciudad de Gijón (mayo 2015) o la Comunidad de Madrid (noviembre 2018). En algunos casos la bicicleta posee un aire decadente como perteneciente a un tiempo pretérito asociado con el pasado y el patrimonio de las ciudades.

También se abordan algunas de las campañas realizadas por las asociaciones probici de España integradas en la Coordinadora Estatal ConBici. Por ejemplo, es destacable la campaña de promoción de la bicicleta diseñada por las asociaciones de Andalucía. Se buscaba la nor-
Figura 11 [izquierda]. Publicidad Institucional. Bicicleta del ayuntamiento de Valladolid. Sistema de Bicicletas Públicas. Año 2019. Figura 12 [derecha]. Publicidad Institucional del ayuntamiento de Salamanca. Fuente: Valla Publicitaria Año 2019. 

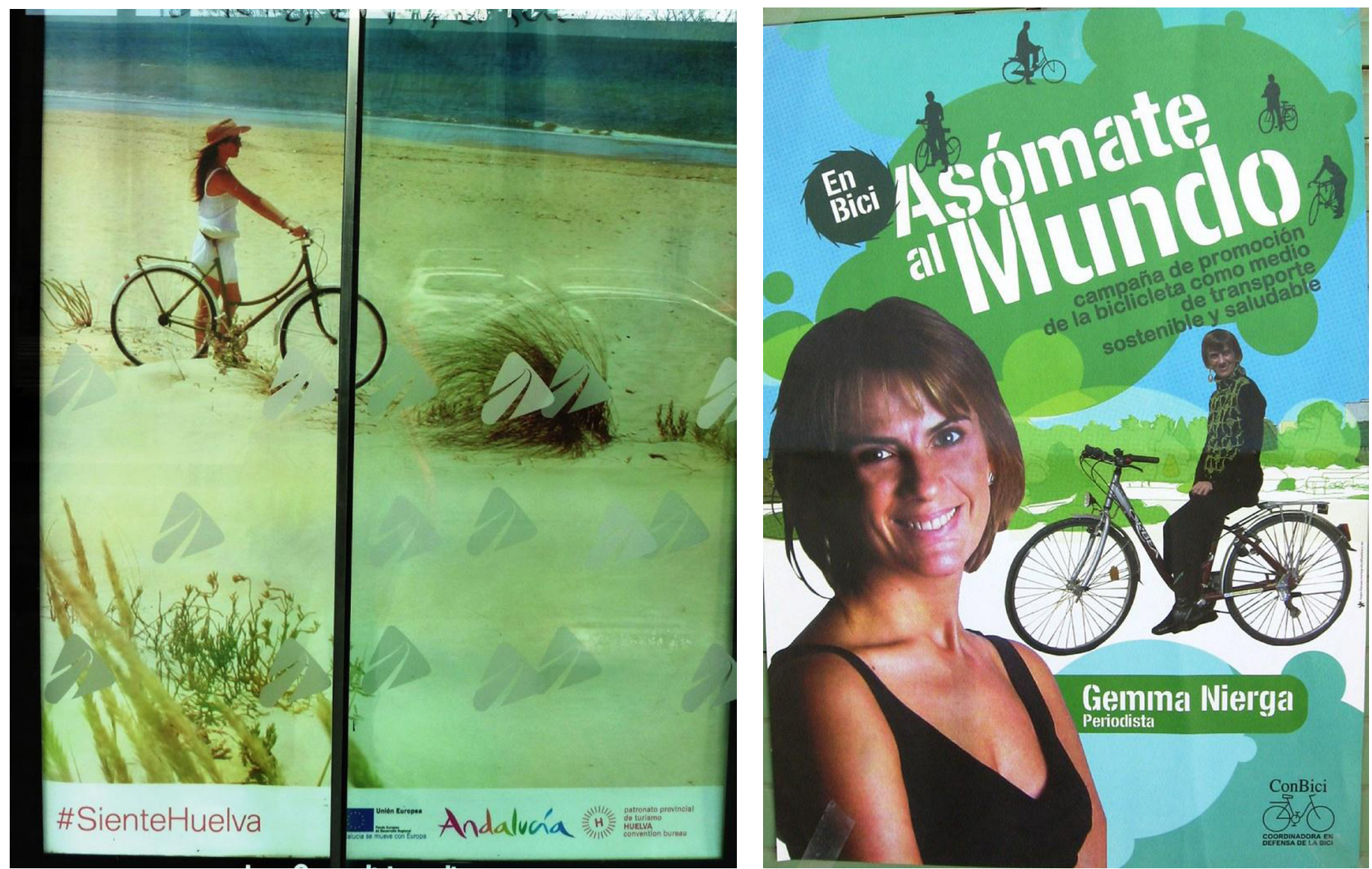

Figura 13 [izquierda]. Publicidad Institucional. Consejería de Turismo de la Junta de Andalucía pagada con fondos europeos. Año 2016 . Figura 14 [derecha]. Campaña de asociaciones probici. Año 2007. Patrocinada por la Junta Andalucía. malización de la bicicleta como medio de transporte mostrando como usuarios a quienes podían reconocerse como "personas de reconocido prestigio" como médicos, periodistas de la radio, actores, cantantes, etc. El lema usado era: "En Bici asómate al mundo. Campaña de promoción de la Bicicleta como medio de transporte sostenible y saludable”. En esta campaña participaron desinteresadamente la periodista Gemma Nierga (Figura 14), la cantante Rakel Winchester o el médico Pedro Benito, jefe del servicio de Endocrinología del Hospital Reina Sofía de Córdoba.

Otra campaña importante fue la realizada por la Coordinadora ConBici patrocinada por el Ministerio de Medio Ambiente (Martín M, 2019) durante el año 2006 (Figura 15). Uno de los lemas era: "Mejor con Bici. Eres inteligente, no hay más que verte, ahorras diariamente sin necesidad de repostar." En esta campaña se promocionaba la bicicleta en ambientes urbanos como por ejemplo un mercado de abastos y se mostraba a usuarios también ataviados de forma corriente, por supuesto no deportiva. "Mejor Con Bici" fue una campaña que informaba sobre todas las ventajas y beneficios de la bicicleta y de su potencial como medio de transporte urbano. Ofrecía consejos prácticos y sencillos sobre cómo iniciarse en el uso de la bicicleta y presenta la bicicleta como una alternativa de movilidad urbana más respetuosa con el entorno y como una apuesta por la calidad de vida en nuestras ciudades.

La contaminación del aire, el ruido y los problemas de movilidad urbana, así como sus efectos y consecuencias para la salud de los ciudadanos y del planeta, ponían de manifiesto la necesidad de pensar y hacer los desplazamientos urbanos, que suelen ser de tres a cinco kilómetros, de otra manera.

La crisis económica del año 2008 y la desaparición de las subvenciones públicas acabó con la mayoría de estas campañas de las organiza- 
ciones civiles que incidían correctamente en su diseño en promocionar la bicicleta como vehículo de transporte en la ciudad.

A la vista de los resultados obtenidos en el análisis de las campañas institucionales, sería muy útil desarrollar guías de comunicación para estas campañas de la administración sobre movilidad sostenible. En este sentido se podrían plantear varios anuncios tipo que reflejen ejemplos de buenas prácticas que deben usar las administraciones.

\section{Publicidad de bicicletas}

A continuación, se pasa a analizar algunos ejemplos de anuncios de empresas de bicicletas. Hace unos quince años (Pedrós-Pérez, 2005) era casi imposible encontrar publicidad comercial de modelos de bicicletas como medio de transporte en los medios de comunicación. En la actualidad con el boom de la bicicleta urbana y de la bicicleta eléctrica y de la existencia de la revista Ciclosfera la situación es muy distinta.

Para analizar la publicidad de la bicicleta en $\mathrm{Ci}$ closfera se han abordado tres números publicados en 2019 correspondientes a primavera, verano y otoño. Dentro de estos tres números se han seleccionado anuncios sobre bicicletas obviando aquellos dedicados a accesorios como candados, alforjas, cascos, etc. Dominan en estos números recientes los anun-

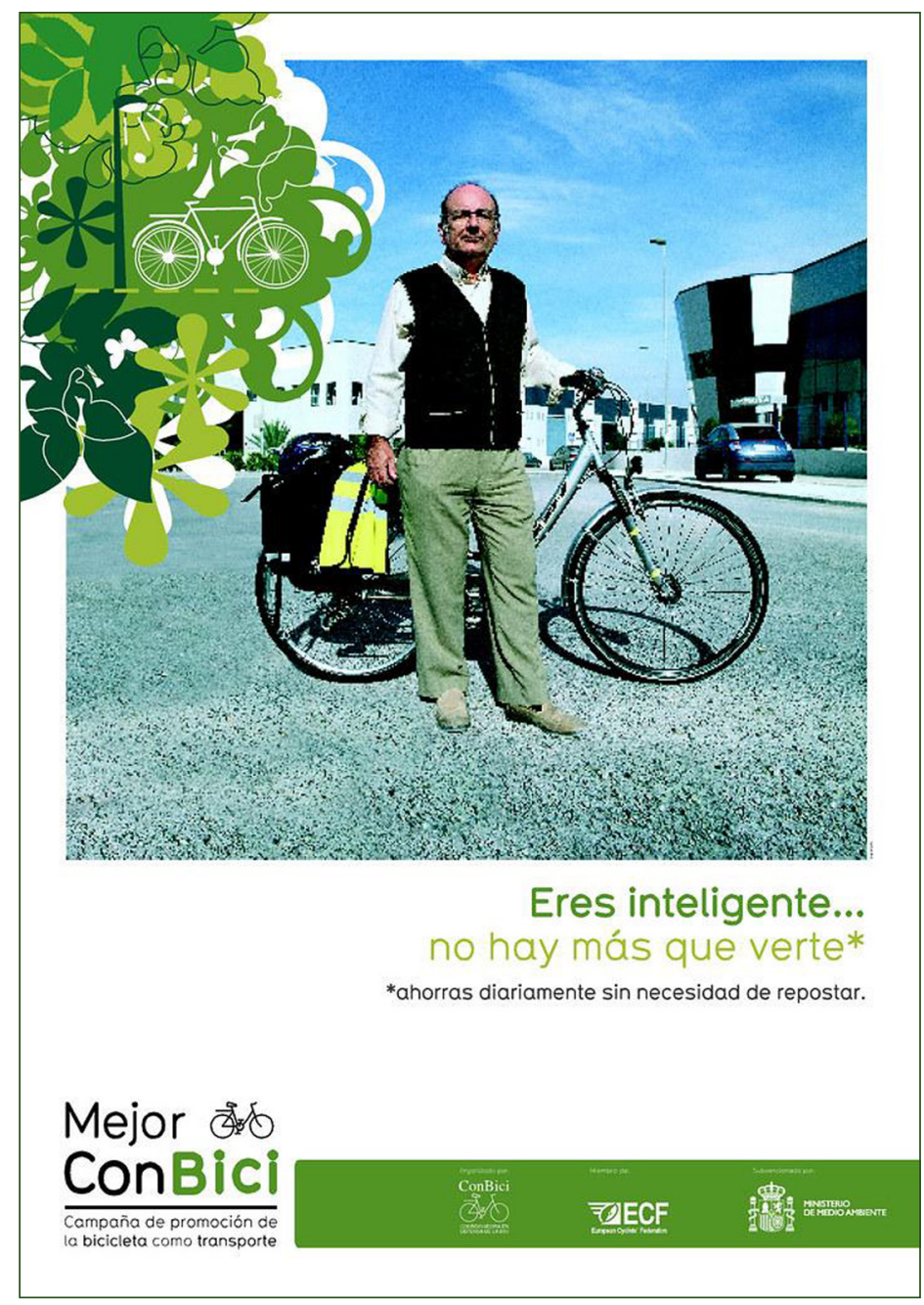
cios de bicicletas eléctricas. Esta promoción de este segmento de bicicletas se justifica en el hecho de que combinar ciudades más amigables con las bicicletas con rápidos avances en la tecnología ha desembocado en un notable aumento en la compra y uso de las bicicletas eléctricas (MacArthur, Dill y Person, 2014).

La muestra analizada comprende 19 anuncios de bicicletas extraídos fundamentalmente de la revista Ciclosfera. Se destacan algunos aspectos muy positivos en cuanto a las argumentaciones usadas en esta publicidad: normalización de la bicicleta como vehículo de transporte $(68 \%)$, vestimenta urbana $(60 \%)$ y presencia de entornos urbanos (58\%). También se han detectado cualidades atribuidas a las bicicletas que coinciden con los eslóganes de la publicidad de los coches identificados en otras investigaciones (Pedrós-Pérez et al., 2019): tecnología $(47 \%)$, diversión (32\%) y gadgets electrónicos (16\%).

Aspectos importantes que tienen muy poca presencia: Ahorro (11\%) y explicitar que la bicicleta es transporte sostenible(5\%). Ítems que ni se nombran a pesar de su presencia cada vez más frecuente en el discurso contemporáneo de la movilidad sostenible: Smart City, salud, cambio climático, calidad del aire y presencia de infraestructura ciclista (carril bici). Casi el $70 \%$ de los anuncios están dedicados a e-bikes.

A continuación, se analizan algunos ejemplos concretos con más detalle. Es una buena elección para desmontar el "estigma" (Aldred, 2013), la imagen que usa la website de la marca Velorbis para publicitar sus bicicletas (Figuras 16 y 17). El mensaje óptimo para transmitir sería que "yo también uso la bicicleta, tú también puedes hacerlo". Se trata de incidir en un cambio en la percepción social de la bicicleta. De for- 

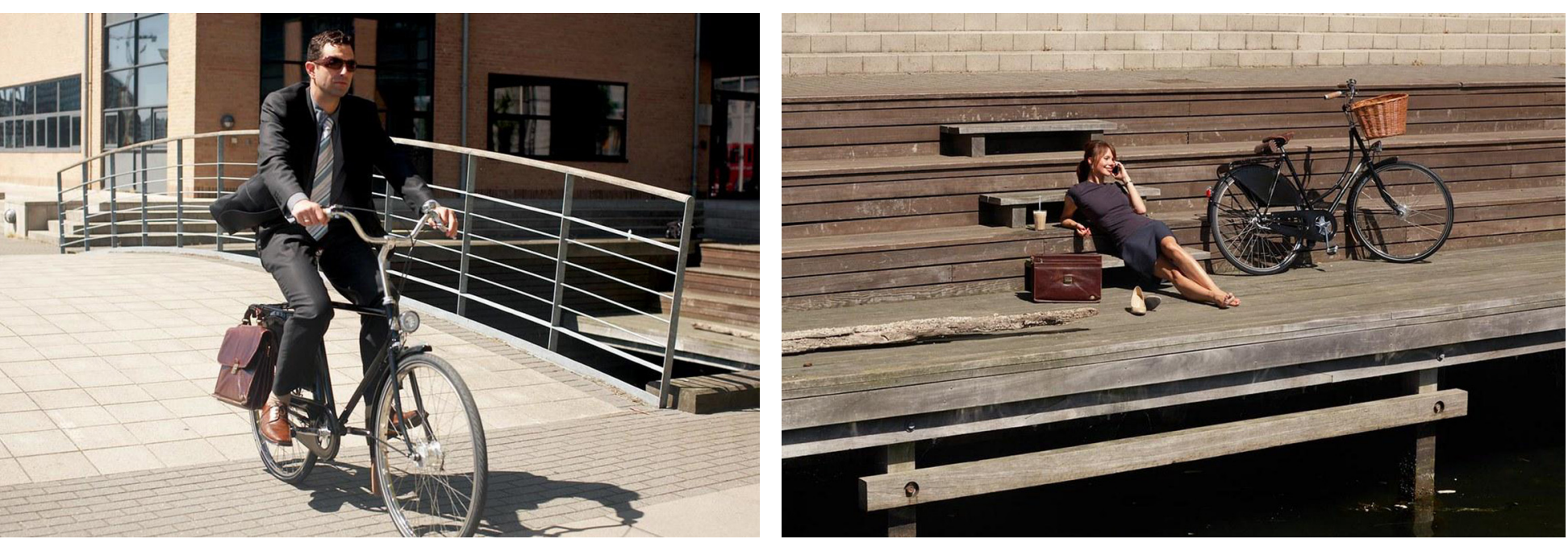

Figura 16 [izquierda]. Publicidad de bicicletas Velorbis. Imagen bajada de la website en el año 2009. Figura 17 [derecha]. Publicidad de bicicletas Velorbis. Imagen bajada de la website en el año 2009 ma que esta se muestre como algo chic que está de moda. De hecho, abundan las páginas de contenido que vinculan este atributo a la bicicleta. Numerosos movimientos nacen inspirados en CopenhagenCycleChic, ${ }^{5}$ movimiento ciclista urbano que defiende el "estilo" sobre la velocidad de desplazamiento.

El anuncio de la bicicleta LivFlourish (Figura 18), una bicicleta de apariencia netamente urbana, con este texto: "LivFlourish: la manera inteligente y con estilo de recorrer la ciudad. Con un diseño funcional y elegante, la Flourish es la bicicleta perfecta para desplazarse por la ciudad. Versátil, ligera, cómoda y con un diseño que hará tus paseos en bici más divertidos". En su mensaje también es destacable que se recurre a algunos argumentos que los autores encontraron como predomi-

\section{LU FLOURISH: LA MANERA INUELIGENUEY CON ESTRLO DE RECORRER LA CIUDAD}

\section{Con un diseño funcional y elegante, la Flourish es la bici perfecta para desplazarse por la ciudad. Versátil, ligera, cómoda y con un diseño que hará tus paseos en bici más divertidos.}

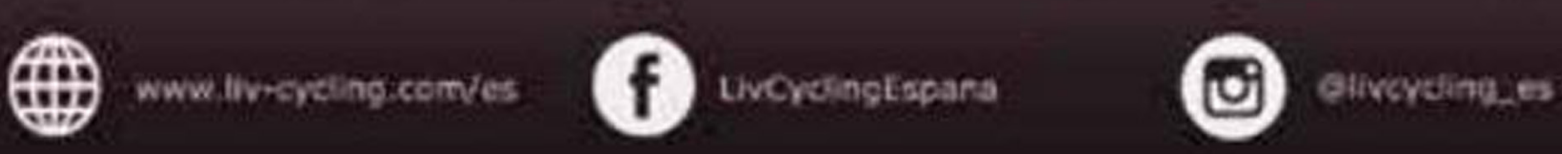

Figura 18. Publicidad de bicicleta Liv Flourish. Imagen de la revista Ciclosfera. Año 2019

5 Cfr. CopenhagenCycleChic nantes en la publicidad de los coches como "la diversión" o el "diseño" (Pedrós-Pérez et al., 2019). Para esta marca en este anuncio especifico la bicicleta es un vehículo orientado al transporte urbano. No obstante, esta marca, si se entra en Facebook o Twitter, está muy orientada al ciclismo deportivo que realizan mujeres.

También incluye bien grande el lema: "Smart and Stylish" asociando la bicicleta con la denominada Smart City. La mayoría de la investigación sobre la "smart mobility" está ampliamente focalizada en el auto- 
móvil e incluye perspectivas muy tecno-céntricas acerca del transporte inteligente. La ideología dominante del "cochismo" está impregnando el discurso del desarrollo de las Smart City según algunos autores (Behrendt, 2019).

Otra marca que se publicita mucho en la revista son las bicicletas Littium; se trata del modelo Berlin Dao, que muestra un entorno urbano nocturno, lo cual es muy poco frecuente en un anuncio de bicicletas y sí muy habitual en la publicidad de coches, y la usuaria es una mujer (Figura 19). El lema: "Belleza Exterior. Tecnología Interior". El argumento tecnológico también es uno de los predominantes en los anuncios de coches, llegando a ser el predominante en las websites de los coches para los años 2015 y 2016 (Pedrós-Pérez et al., 2019). Si se entra en la Web de Littium ${ }^{6}$ (Littium, 2020) el argumento dominante es "La apuesta Vintage de Littium".

La imagen de bicicleta urbana se capta enseguida en este anuncio de bicicletas Littium (Figura 20) por el entorno de calle en que aparece y por la vestimenta de los usuarios, alejada de los llamados "ciclistas que van de bonito", adjetivo con el que muchos usuarios se refieren a los ciclistas deportivos que a veces parecen provenir de un desfile de moda deportiva. El argumento principal que utiliza viene ligado al ahorro, al menor consumo: "100 kilómetros de autonomía por cinco céntimos". Ya en letra más pequeña: "descubre el futuro de la movilidad eléctrica". Poniendo una pica en Flandes con este último lema contra la habitual identificación reduccionista que se hace entre movilidad eléctrica y coches eléctricos. En el futuro para que la e-bike tenga su propia identidad es necesario desarrollar un lenguaje propio para las e-bikes que les dé visibilidad, que podría ser e-velomobility o e-velomobility. ¿Qué justifica esta distinción? El discurso mainstream sobre e-mobility está totalmente escorado hacia el coche, identificando movilidad eléctrica con automóvil, por eso es necesario expandir y reforzar el discurso de la e-velomobility (Behrend, 2018).

Así, en la actualidad en la publicidad de los coches eléctricos se muestra como solución ambiental los poderosos todoterrenos eléctricos como vehículos ideales para la Smart City. Por ejemplo, anunciando el "nuevo Hyundai Kona eléctrico" cuyo peso es de 1500 kilogramos y el hibrido $1376 \mathrm{~kg}$. Sería deseable destacar en la publicidad de las $e^{-}$

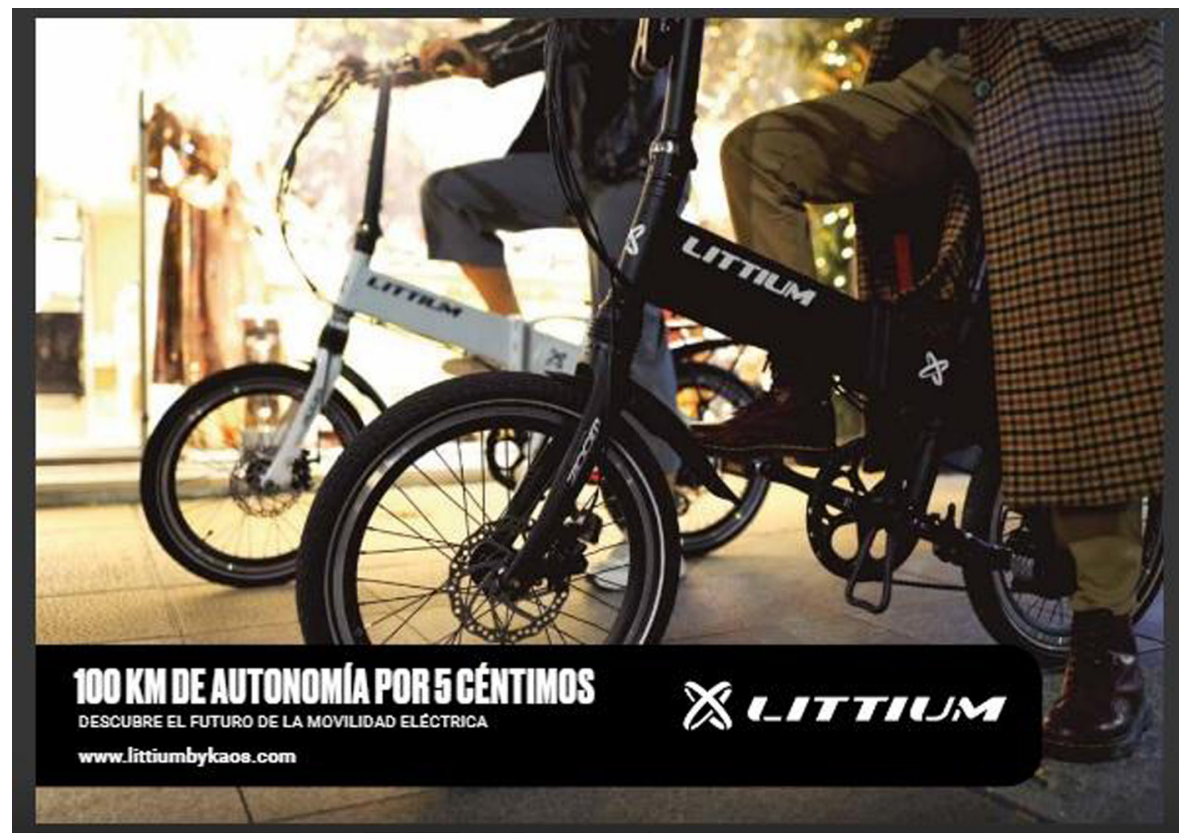

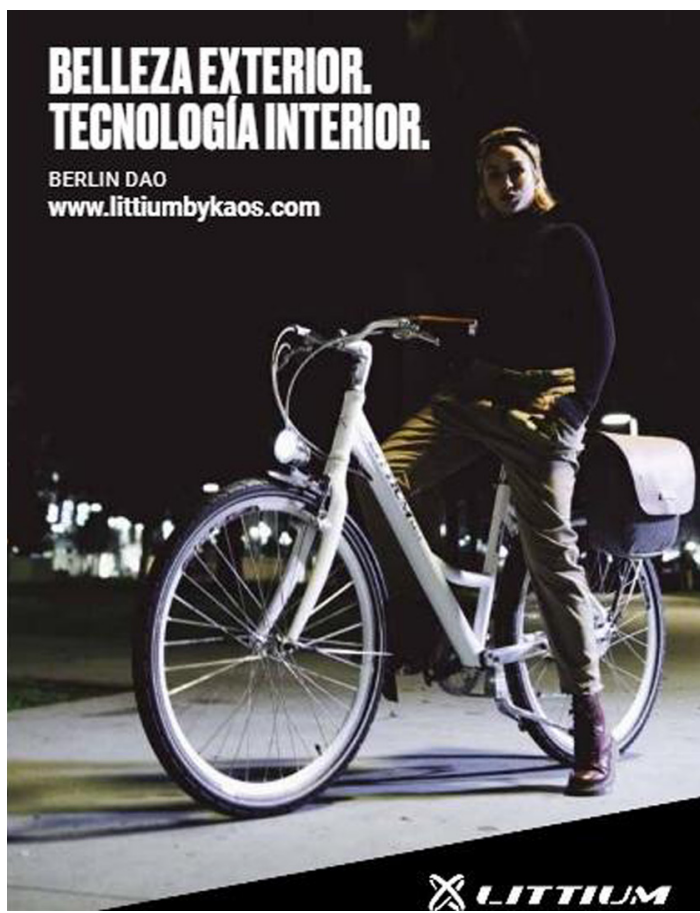

Figura 19. Publicidad de bicicleta Littium. Imagen de la revista Ciclosfera. Año 2019.

Figura 20. Publicidad de bicicleta Littium plegable eléctrica. Revista Ciclosfera. Año 2019. 


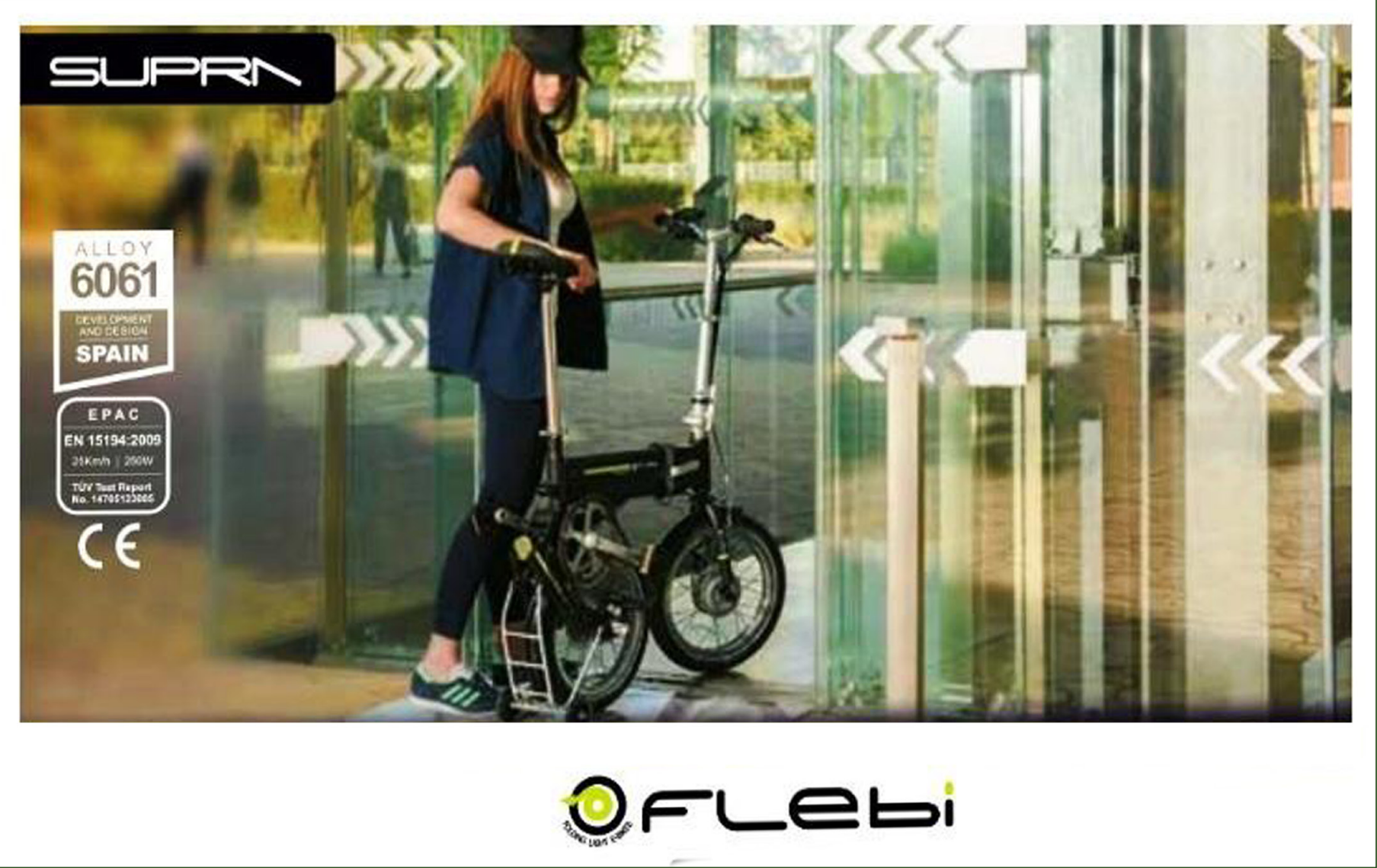

Figura 21. Publicidad de Bicicleta Flebi. Imagen de la revista Ciclosfera. Año 2019 bikes este argumento ligado a la eficiencia: comparar estos pesos de los automóviles eléctricos con el de una bicicleta eléctrica cuyo promedio es de $25 \mathrm{~kg}$.

Si se aborda la publicidad de la bicicleta Berlín Dao se encuentra este texto en la Web:

Berlín lleva integrada la tecnología DAO que permite administrar la potencia al motor adaptándose a la conducción de cada usuario, gracias a ello, se consigue optimizar la potencia de la e-bike. Al gestionarse por sí solo, no es necesario el tradicional display en el manillar, por lo que Berlín se puede considerar la primera bicicleta eléctrica $100 \%$ libre de cables. Es posible gestionar la potencia de modo manual. Se realiza mediante un controlador bluetooth vinculado al teléfono del usuario a través de una app de gestión.

Un texto muy similar el anterior de la bicicleta Berlín es el que se identifica en los anuncios de coches que destacan también los llamados gadgets en un 83\% para los vehículos a motor (Pedrós-Pérez et al., 2019):

Todas las bicicletas eléctricas tienen un exceso de cableado, este es el motivo principal por el que hemos desarrollado un nuevo concepto de bicicleta. El modelo Berlín dispone de toda la potencia de una buena bicicleta eléctrica pero la interfaz entre la bicicleta y el usuario ha desaparecido.

En la publicidad en la revista de la marca Flebi (Figura 21) se muestra a una usuaria con una bicicleta plegable vestida de ciudad. En la website de las bicicletas plegables Flebi aparece este texto donde se sitúa a la bicicleta con la cualidad transporte sostenible: 
Un innovador concepto de transporte sostenible que combina tres características principales. Tienen un tamaño muy compacto tras plegarse, pesan muy poco para que la puedas transportar con comodidad y cuentan con un sistema eléctrico para que te desplaces sin esfuerzo.

En otros textos se destaca sobre todo la comodidad del plegado, importante para facilitar la intermodalidad coche-bicicleta o transporte público-bici.

¿Por qué Flebi? Se pliega fácil y rápido. Con un click ya tienes tu bici reducida a la mitad de tamaño para guardarla donde quieras.

Llévala contigo. Empújala semiplegada o arrástrala como un trolley. Y si tienes que levantarla, pesa muy poco. Disfruta la asistencia. Alta potencia y larga autonomía para desplazarte sin esfuerzo de forma limpia y divertida.

Cabe destacar que los autores han observado que en los trenes en Andalucía cada vez acceden más usuarios con bicicletas plegables que practican la intermodalidad.

Abordando otra marca, las bicicletas eléctricas de paseo Winora Sinus Tria 8. El texto es el siguiente: "Una bicicleta eléctrica confort con motor central Bosch Performance Cruise de 60 Nm. Comodidad y elegancia para una vida urbana" (Extraído de Twitter).

En cuanto a la marca de bicicletas Giant Express Way: “¿Quién dijo que los trayectos diarios son rutinarios? Convierte tus desplazamientos cotidianos en aventuras con esta elegante bicicleta plegable". Un texto muy similar al que aparece a veces en la publicidad de los coches como este en la Web de El País Motor: "Los 15 coches más divertidos para disfrutar de una carretera con curvas. Los mejores modelos para saborear recorridos sinuosos exprimiendo el motor (respetando siempre las normas, por supuesto)"(COG, 2017).

Concluyendo, la publicidad de bicicletas analizada opta por buenas prácticas como mostrar que la bicicleta en la ciudad como medio de transporte está de moda y es apropiada para que la usen "gente de reconocido prestigio". Otras buenas prácticas, aunque escasas, identifican la bicicleta como un elemento de ahorro económico y como transporte sostenible.

Faltan referencias en la publicidad de las marcas de bicicletas a la construcción de la Smart City, a la cuestión ambiental y a las ventajas respecto de la salud. Sería muy recomendable introducir eslóganes sobre movilidad activa o vehículo cero emisiones. Cierta publicidad recurre a lemas parecidos a los de los automóviles.

\section{Conclusiones}

Las lógicas limitaciones de esta investigación han permitido detectar ciertas tendencias que pueden servir de base para posteriores investigaciones de la comunidad científica. Los resultados de este trabajo pueden servir de incentivo para que las empresas de bicicletas mejoren sus estrategias de comunicación enfocadas en la movilidad sostenible.

Sería muy útil también desarrollar guías de comunicación para la publicidad institucional sobre movilidad sostenible. En este sentido se podrían plantear varios anuncios tipo que reflejen ejemplos de buenas prácticas que deben usar las administraciones. Es importante que estas campañas institucionales hagan hincapié en la faceta correspondiente 
a la adaptación al cambio climático, en las subidas de temperatura y en las olas de calor que harán que los episodios de contaminación sean más frecuentes, destacando la necesidad de la restricción del uso del coche y la promoción del uso habitual de la bicicleta.

El papel de la bicicleta en productos no relacionados con la movilidad suele ser sinónimo de mejor comunicación entre las personas, transporte, diversión y elemento saludable. La publicidad de los coches presenta el automóvil como el modo de transporte normativo y habitual, infravalorando o incluso despreciando a la bicicleta como vehículo. Se detectan algunos anuncios de coches que presentan la bicicleta como un elemento pasivo, fuera de las opciones de movilidad y como un vehículo de riesgo que se libra de los accidentes gracias a los numerosos gadgets electrónicos que incorporan los modernos automóviles. No se han detectado tampoco anuncios de automóviles donde se fomente la intermodalidad bicicleta coche, una solución eficaz al transporte urbano especialmente en las grandes ciudades.

La bicicleta ha de mostrar en su publicidad que es un elemento que contribuye a la mitigación y a la adaptación frente al cambio climático. Se ha de insistir más en la cuestión ambiental y de salud en la publicidad de las marcas de bicicletas, introduciendo eslóganes sobre movilidad activa o vehículo cero emisiones. Se han detectado buenas prácticas donde la bicicleta se muestra como un vehículo chic y elegante. Cierta publicidad recurre a lemas parecidos a los de los automóviles como gadgets electrónicos, diversión, diseño, libertad; esto tiene sus aspectos positivos y negativos.

La industria del automóvil hace del concepto Smart City una estrategia corporativa para proyectarse como un interlocutor imprescindible si una ciudad quiere ser urbe inteligente, exigiendo por ejemplo que las administraciones coloquen puntos de recarga. Debajo del discurso Smart subyace la tendencia a fetichizar cierto tipo de prácticas, infraestructuras y tecnologías en detrimento de otras que permanecen invisibles y escondidas debajo del tejido urbano, como la bicicleta y el caminar, pero que hacen la vida posible en la ciudad, a la vez que estructuran la cotidianeidad que se experimenta(March, Ribera-Fumaz y Elías, 2016). La bicicleta en la publicidad ha de pregonarse por tanto como un elemento imprescindible en la Smart City.

El discurso mainstream sobre e-mobility está totalmente escorado hacia el coche, identificando movilidad eléctrica con automóvil, por eso es necesario expandir y reforzar el discurso de la e-velomobility en la publicidad de las bicicletas eléctricas. Las administraciones deben también promocionar las bicicletas eléctricas, dado el escoramiento actual de las instituciones hacía el coche eléctrico. 


\section{Referencias bibliográficas}

Agencias, S.N (2018, 23 de abril). Carmena gana el pulso a las eléctricas en la exigencia de fuentes renovables. Diario El País. Recuperado el 24 de febrero de 2020 de: https:/ / elpais.com/ ccaa/2018/04/23/madrid/1524474837_597501. html.

Aldred, Rachel (2013). Incompetent or too competent? Negotiating everyday cycling identities in a motor dominated society. Mobilities, 8(2), 252-271. DOI: 10.1080/17450101.2012.696342.

Amato, Fulvio; Pandolfi, Marco; Escrig, Alberto; Querol, Xavier; Alastuey, Andrés; Pey, Jorge; Pérez, Noemi; y Hopke, Philip K. (2009). Quantifying road dust resuspension in urban environment by multilinear engine: a comparison with PMF2. Atmospheric Environment, 43(17), 2770-2780. DOI: 10.1016/j.atmosenv.2009.02.039.

Atkinson, Lucy (2014). Green moms: the social construction of a green mothering identity via environmental advertising appeals. Consumption Markets $\mathcal{E}^{\circ}$ Culture, 17(6), 553-572. DOI: 10.1080/10253866.2013.879817.

Atkinson, Lucy; y Kim, Yoojung (2015). "I Drink It Anyway and I Know I Shouldn't”: Understanding Green Consumers' Positive Evaluations of Normviolating Non-green Products and Misleading Green Advertising. Environmental Communication, 9(1), 37-57. DOI: 10.1080/17524032.2014.932817

AUC (2004). Asociación de Usuarios de la Comunicación. Publicidad y Medio Ambiente. Recuperado el 24 de febrero de 2020 de: http:/ / www.auc.es/Paginas $/$ download.php? type $=$ doc $\&$ year $=2004 \&$ file $=$ doc u26.pdf

Autocontrol (2016). Asociación para la Autorregulación de la Publicidad Comercial. Recuperado el 10 de febrero de 2016 de: http:/ / www.autocontrol.es.

Behrendt, Frauke (2018). Why cycling matters for electric mobility: towards diverse, active and sustainable e-mobilities. Mobilities, 13(1), 64-80. DOI: 10.1080/17450101.2017.1335463.

Behrendt, Frauke (2019). Cycling the smart and sustainable city: analyzing EC policy documents on internet of things, mobility and transport, and smart cities. Sustainability, 11(3), 763. DOI: 10.3390/ su11030763.

Botey López, Jorge; Martín Guart, Ramón; y Rom Rodríguez, Josep (2013). La sostenibilidad como eje de la cultura empresarial de las marcas: el caso de los 'e-car'. Historia y Comunicación Social, 18 (núm. Especial diciembre), 529-547. DOI: 10.5209/rev_ HICS.2013.v18.44347.

Carse, Andrew; Goodman, Anna; Mackett, Roger L.; Panter, Jenna; y Olgivie, David (2013). The Factors influencing car use in a cycle-friendly city: the case of Cambridge. Journal of Transport Geography, 28(C), 67-74. DOI: 10.1016/j.jtrangeo.2012.10.013.

CENEAM (2018).XV Seminario Respuestas desde la Comunicación y la Educación al Cambio Climático. Segovia. Recuperado el 5 de marzo de 2020 de: https:/ / www.miteco.gob.es/es/ceneam/grupos-de-trabajoy-seminarios / respuestas-desde-la-educacion-y-la-comunicacion-al-cambio-climatico/15-seminario-cambio-climatico.aspx.

C.O.G. (2017). Los 15 coches más divertidos para disfrutar de una carretera con curvas. Motor El País. Recuperado el 25 de febrero de 2020 de: https:/ / motor.elpais.com/conducir/coches-divertidos-carretera-con-curvas/.

ECODES (2020). La desproblematización del cambio climático, e incluso la negación de su existencia, están presentes en la publicidad. Observatorio de Publicidad Responsable frente al cambio climático. Recuperado el 11 de marzo del 2020 de: https:/ / ecodes.org/ hacemos/cambio-climatico/adaptacion/observatorio-de-publicidad-responsable-frente-al-cambio-climatico/en-que-consiste.

EFE (2019, 6 de octubre). La retirada de Endesa del carbón dejará sólo tres térmicas activas en la Península. Diario Expansión. Recuperado el 24 de febrero del 2020 de: https://www.expansion.com/empresas/energia/2019/10/06/5d99c355e5fdead2378b 46e1.html.

European Environment Agency (2011). Report on the implementation of Directive 1999/94/EC relating to the availability of consumer information on fuel economy and CO2 emissions in respect of the marketing of new passenger cars. Recuperado el 27 de enero de 2019 de: https:/ / ec.europa.eu/clima/sites/clima/files/transport/vehicles/labelling/docs/final_report_2012_en.pdf.

Fishman, Elliot y Cherry, Christopher (2016). Ebikes in the Mainstream: Reviewing a Decade of Research. Transport Reviews, 36(1), 72-91. DOI: 10.1080/01441647.2015.1069907.

Fowler III, Aubrey R.; y Close, Angeline G. (2012). It ain't easy being green: Macro, meso, and micro green advertising agendas. Journal of Advertising, 41(4), 119-132. DOI: 10.1080/00913367.2012.10672461.

Gal-Tzur, Ayelet; Grant-Muller, SusanM.;Kuflik, Tsvi;Minkov, Einat; Nocera, Silvio; y Shoor, Itay(2014). The potential of social media in delivering transport policy goals. TransportPolicy, 32, 115123. DOI: 10.1016/j.tranpol.2014.01.007.

García Martín, Miguel A. (2018). ¿Te gusta conducir? Una mirada crítica desde la publicidad de coches y 
su retórica medioambiental. Didáctica de las Ciencias Experimentales y Sociales, 34, 91-104. DOI: 10.7203/ DCES.34.11008.

Goulden, Murray;Ryley, Tim; y Dingwall, Robert (2014). Beyond 'predict and provide': UK transport, the growth paradigm and climate change. Transport Policy, 32, 139-147. DOI: 10.1016/j.tranpol.2014.01.006.

Haufe, Nadine; Millonig, Alexandre; y Markvica, Karin (2016). Developing encouragement strategies for active mobility. Transportation research procedia, 19, 49-57. DOI: 10.1016/j.trpro.2016.12.067

Herráez, Mario (2020, 21 de febrero). El Opel Astra reduce un $21 \%$ sus emisiones de $\mathrm{CO}_{2}$. El Pais Motor. Recuperado el 21 de febrero del 2020 de: https:/ / motor.elpais.com/actualidad/opel-astra-reduceemisiones/.

Jiménez Gómez, Isidro. (2017). Hablemos del tiempo. El imaginario publicitario del cambio climático. Ámbitos, Revista Internacional de Comunicación, 37, 1-12.

Jiménez Gómez, Isidro y Martín-Sosa Rodríguez, Samuel. (2018). El estudio del cambio climático en la prensa a través de sus efectos: una propuesta metodológica. En Rodrigo-Cano, D., De-CasasMoreno, P. y Toboso-Alonso, P.(eds.), Los medios de comunicación como difusores del cambio climático (pp. 107-122). Zaragoza: Egregius Ediciones.

Leonidou, Leonidas C.; Leonidou, Constantinos N.; Palihawadana, Dayananda; y Hultman, Magnus (2011). Evaluating the green advertising practices of international firms: a trend analysis. International Marketing Review, 28(1), 6-33. DOI: $10.1108 / 02651331111107080$.

Leonidou, Leonidas C.;Leonidou, Constantinos N.;Hadjimarcou, John S.; y Lytovchenko, Irina (2014). Assessing the greenness of environmental advertising claims made by multinational industrial firms. Industrial Marketing Management, 43(4), 671684. DOI: 10.1016/j.indmarman.2014.02.003.

March Corbella, Hug; Ribera-Fumaz, Ramón; y Vivas Elías, Pepo (2016). Crisis, ciudad y tecnología ¿una solución inteligente? Ciudad y Territorio Estudios Territoriales (CyTET), 48(187), 239-248.

MacArthur, John; Dill, Jennifer y Person, Mark (2014). Electric bikes in North America: results of an online survey. Transportation Research Record: Journal of the Transportation Research Board, 2468, 123-130. DOI: $10.3141 / 2468-14$.

Martín, Manuel (2019). Así fue la campaña «Mejor Con Bici» de 2006. ConBici. Recuperado el 5 de marzo de 2020 de: https:/ / conbici.org/eventos/ asi-fue-la-campana-mejor-con-bici-de-2006.

Megías Delgado, Mario; Baldallo González, Carmen y Maraver López, Pablo (2018). Validez de la publicidad como recurso en la Educación Ambiental. Revista Mediterránea de Comunicación/ Mediterra-
neanJournal of Communication, 9(2), 203-215. DOI: $10.1590 / \mathrm{s} 1517-9702201703155092$

Nyilasy, Gergely.;Gangadharbatla, Harsha; y Paladino, Angela (2014). Perceived greenwashing: The interactive effects of green advertising and corporate environmental performance on consumer reactions. Journal of Business Ethics, 125(4), 693-707. DOI: $10.1007 / \mathrm{s} 10551-013-1944-3$.

OAPM (2020). Observatorio Andaluz de la Publicidad No Sexista. Instituto Andaluz de la Mujer. Conserjería de Igualdad, Politica Sociales y Conciliación.Recuperado el 13 de enero de 2020 de: http:/ /www. juntadeandalucia.es/iamindex.php/observatorioandaluz-de-publicidad-no-sexista/bienvenida-al-observatorio-andaluz-de-publicidad-no-sexista.

Pedrós-Pérez, Gerardo (2005). El Observatorio de la publicidad de la movilidad sostenible y la televisión. Comunicar, 13(25). DOI: 10.3916/C25-2005-088.

Pedrós-Pérez, Gerardo (2014). Observatorio Publicidad: La Bicicleta usada en la publicidad de un vino. BlogOtraCordobaesposible. Recuperado el 13 de enero de 2020 de: https:/ / otracordobaesposible.wordpress.com/2014/08/13/la-bicicleta-usada-en-la-publicidad-de-un-vino/

Pedrós-Pérez, Gerardo (2018). Observatorio de la Publicidad de la Movilidad. Nissan Leaf. Poco medioambiente y mucha diversión y gadgets. OtraCórdobaesposible. Recuperado el 13 de enero de 2020 de: https:/ / otracordobaesposible.wordpress. com/2018/05/07/observatorio-publicidad-movilidad-nissan-leaf-poco-medioambiente-y-mucha-diversion-y-gadgets/

Pedrós-Pérez, Gerardo y Martínez-Jiménez, Pilar (2010). Publicidad, educación ambiental y calentamiento global. En Heras, F. et al. (coord.), Educación ambiental y cambio climático: Respuestas desde la comunicación, educación y participación ambiental (pp. 101-118). CEIDA: Centro de Extensión Universitaria e Divulgación Ambiental de Galicia.

Pedrós-Pérez, Gerardo; Martínez-Jiménez Pilar y Aparicio-Martínez, Pilar (2019). The potential of car advertising in pursuing transport policy goals: Code of good practices in the Spanish context. Transportation Research Part D: Transport and Environment, 72, 312-332. DOI: 10.1016/j.trd.2019.05.010.

Sabre, María Elisa (2014). La publicidad verde en Argentina. Análisis del uso de apelaciones medioambientales en anuncios televisivos. Cuadernos.Info, 34, 27-38. DOI: $10.7764 /$ cdi.34.544.

Sánchez Revilla, María Elisa (2018). Estudio Info Adex de la inversión publicitaria en España 2018. Madrid: InfoAdex.

Scopa, Pasquale; Scapellato, Maria Luisa; Perissinotto, Egle; Trevisan, Andrea; Carrieri Mariella; y Bartolucci, Giovanni Battista (2016). The greenhouse gas automotive advertisement study. Transport Policy, 45, 77-85. DOI: 10.1016/j.tranpol.2015.09.009. 
Marqués Sillero, Ricardo (2017). La importancia de la bicicleta: un análisis del papel de la bicicleta en la transición hacia una movilidad urbana más sostenible. Sevilla: Universidad de Sevilla.

Urry, John (2010). Consuming the Planet to Excess. Theory, Culture E Society, 27, 191-212. DOI: $10.1177 / 0263276409355999$.

Wilson, Nick; Maher, Anthony; Thomson, George y Keall, Michael (2008). Vehicle emissions and con- sumer information in car advertisements. Environmental Health 7, 1-6. DOI: 10.1186/1476-069X-714.

Wynes, Seth; y Nicholas, Kimberly A. (2017). The climate mitigation gap: education and government recommendations miss the most effective individual actions. Environmental Research Letters, 12(7), 074024. DOI: 10.1088/1748-9326/aa7541.

Pedrós-Pérez, Gerardo; Martínez Jiménez, Pilar; y Aparicio Martínez, Pilar (2020). La imagen de la Bicicleta en la comunicación publicitaria: movilidad sostenible y cambio climático. Hábitat y Sociedad, 13, 125-149.

<http://dx.doi.org/10.12795/HabitatySociedad.2020.i13.08>

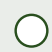




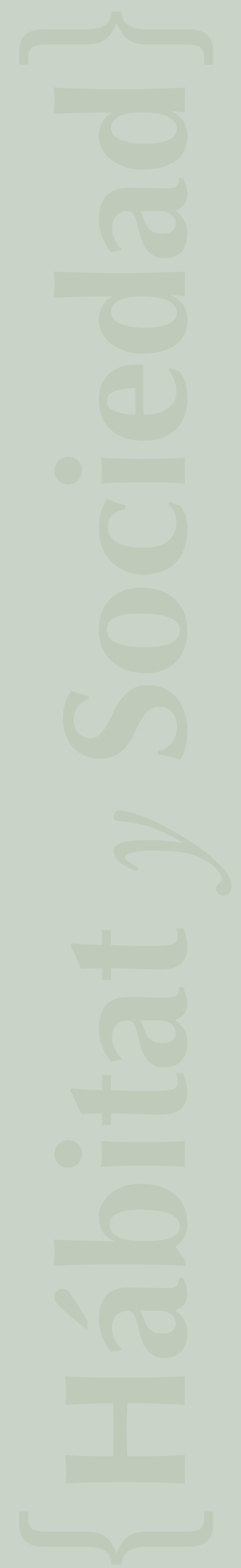

